[Note: the following is an open-access version of an article originally published in Shakespeare Quarterly 68, no. 1 (2017): 21-55, as part of a tribute to our friend and mentor, Barbara Mowat. Please use the published version when citing.]

\title{
Moving Parts: Digital Modeling and the Infrastructures of Shakespeare Editing
}

\author{
Alan Galey and Rebecca Niles
}

When we mean to build,

We first survey the plot, then draw the model, And when we see the figure of the house, Then must we rate the cost of the erection, Which if we find outweighs ability, What do we then but draw anew the model In fewer offices, or at least, desist To build at all? -2 Henry IV, 1.3.43-501

Modeling points the way to a computing that is of as well as in the humanities: a continual process of coming to know by manipulating representations.

-Willard McCarty ${ }^{2}$

Among Barbara Mowat's many contributions to Shakespearean editing, one that holds particular consequence for digital scholars is her insistence that all of Shakespeare's dramatic writing that we have inherited is unavoidably mediated by printing as a complex mechanical process. ${ }^{3}$ Looking back to the history of Shakespeare editing over

Portions of this essay were presented by Alan Galey in a paper for the "Temporalities and Technologies" panel at the 2017 Shakespeare Association of America (SAA) meeting in Atlanta, GA and in the "Shakespeare and Book Design" seminar at the 2015SAA meeting in Vancouver, BC. The authors wish to thank Paul Werstine, Michael Poston, Peter Blayney, and Sarah Werner in particular, as well as the Folger Shakespeare Library's scholarly community more broadly as a supportive context for this research. This essay is dedicated with appreciation and affection to Barbara Mowat.

${ }^{1}$ Unless otherwise noted, quotations from Shakespeare are taken from Barbara Mowat, Paul Werstine, Michael Poston, and Rebecca Niles, eds., Shakespeare's Plays, Sonnets, and Poems (Washington, DC: Folger Shakespeare Library, n.d.), http:// www.folgerdigitaltexts.org.

${ }^{2}$ Willard McCarty, "Modeling: A Study in Words and Meanings," in A Companion to Digital Humanities, ed. Susan Schreibman, Ray Siemens, and John Unsworth (Malden, MA: Blackwell, 2004), 254-70, esp. 265.

${ }^{3}$ The one potential exception to this claim (thus far) is Shakespeare's debated identity as Hand D in the surviving manuscript for the play Sir Thomas More. For a recent intervention in this debate, see Michael 
the twentieth century and earlier, Mowat argues that "there has been from the beginning an editorial sacralizing of lost authorial manuscripts that has made us frame the problem of Shakespeare's texts incorrectly." ${ }^{4}$ Our purpose here is not to retell this story but to follow a less obvious thread leading from another part of Mowat's argument, when she claims that "to abandon the figurative search for Shakespeare's manuscripts and to accept that we have nothing but the printed texts themselves ... . will mean rethinking the foundations of Shakespeare editing. ${ }^{5}$ Mowat's work in editorial theory reflects the foundational premises of analytical bibliography, but her argument also informs our understanding of digital editing and its dependence on data modeling: the Shakespeare we have continues to be mediated by complex technological systems, and the mechanical process that Mowat describes is in many ways still ongoing, albeit with new machines. If post-New Bibliographical editorial theory and practice mean letting go of hypothetically reconstructed Shakespeare manuscripts, then we must learn to live with the fundamental printedness of Shakespeare texts-especially if we encounter them innocently reprinted, as it were, on a digital screen.

A literal, tactile reminder of the mechanical nature of printing can be had simply by running one's fingers across the printed pages of a letterpress book, whose words have been printed not on paper but in it, with a force achievable only by a machine. Just as the leaves of early modern printed books register the impressions of type in three dimensions, not just two, so do our inherited Shakespeare texts bear the marks of their mechanical transmission. Scholars have responded differently to the printedness of Shakespeare texts; some eighteenth-century editors despaired over the corrupting influence of printing on textual transmission, while some late twentieth-century scholars embraced textual materiality and the meaning-making potential of textual agents beyond the traditional author-genius. ${ }^{6}$ Both responses, however, agree that printed Shakespeare texts are artifacts: they are constructed by human hands working in a mechanical process, embedded in a social world that includes Shakespeare's theaters and playing companies, and not simply emanations from an author's mind. The word data hardly does them justice.

One could divide digital Shakespeare scholarship into that which reckons with this difficult truth and that which does not. We here consider the ongoing mechanical mediation of Shakespeare, specifically in the form of connections between editorial labor and editorial infrastructures-print, manuscript, and digital-and their consequences for the artifactuality of Shakespeare texts. The idea of the model is key to understanding the nature of built objects, whether texts or houses, as Lord Bardolph unfolds in 2 Henry IV in a passage that Shakespeare himself built out of materials he found in the Gospel of Luke (see the first epigraph). ${ }^{7}$ Shakespeare editing and analytical

L. Hays, "Shakespeare's Hand Unknown in Sir Thomas More: Thompson, Dawson, and the Futility of the Paleographic Argument," Shakespeare Quarterly 67.2 (2016): 180-203.

${ }^{4}$ Barbara Mowat, "The Problem of Shakespeare's Text(s)," in Textual Formations and Reformations, ed. Laurie E. Maguire and Thomas L. Berger (Newark: U of Delaware P, 1998), 131-48, esp. 133.

${ }^{5}$ Mowat, “Problem of Shakespeare's Text(s)," 139 (emphasis added).

${ }^{6}$ On eighteenth-century editors' pessimism about the reliability of Shakespeare's texts, see Andrew Murphy, Shakespeare in Print: A History and Chronology of Shakespeare Publishing (Cambridge: Cambridge UP, 2003), 81-82. For a contrasting approach toward what Pope and Johnson would have regarded as textual corruption, see Margreta de Grazia and Peter Stallybrass, "The Materiality of the Shakespearean Text," Shakespeare Quarterly 44.3 (1993): 255-83.

${ }^{7}$ See the parable of the builder in Luke 14:28-30, in The Geneva Bible: A Facsimile of the 1560 Edition (Peabody, MA: Hendrickson Bibles, 2007). On Shakespeare's own use of the Geneva Bible as a source of literary building materials, see Barbara Mowat, "Shakespeare Reads the Geneva Bible," in Shakespeare, 
bibliography have, to a great extent, been modeling the relationships between texts, machines, and humans in various ways since the rise of the New Bibliography in the early twentieth century, and understanding this history is essential for any digital modeling efforts in the present. This essay will attempt to explain why.

Our aim is to position the study of Shakespeare's mechanical mediation on a continuum reaching into the present age of digital editing, and thus to resist the tendency to regard digital Shakespeare editing as a radical break with older practices. Even in 2017, digital technologies are often considered in isolation from history, which may lead to deterministic, uncritical, or unhistoricized claims for the potentials of digital editing. Instead, we consider the infrastructures already in the ground beneath the feet of digital editors, as it were-the tools and techniques that editors use to construct models of their texts, and information architectures by which readers will experience the results of editorial labor. How do the working practices of editors shape editions? To what extent does available infrastructure determine editorial theory, or vice versa? What does a basic editorial concept like precision mean in the context of technologies like XML that allow us, paradoxically, to make rigorously formal models of textual ambiguity? In other words, this essay will ask what a bibliographical and book-historical perspective can reveal when turned on digital editions themselves as artifacts in the long continuum of mechanical production that Mowat calls on us to imagine for Shakespeare's texts. ${ }^{8}$

We ask these questions from our own shared perspectives as bibliographers and book historians who are also text encoders and interface designers, and who have advised on various Shakespeare projects, including Folger Digital Texts (FDT), the Internet Shakespeare Editions (ISE), the Electronic New Variorum Shakespeare (ENVS), and most recently the Arden Shakespeare's planned Fourth Series. ${ }^{9}$ It is possible to serve as a text encoder or another kind of digital humanist on a Shakespeare project while taking almost no interest in the history of the texts, as is frequently the case in data-mining and other macro-analytical approaches. However, even a passing familiarity with Shakespearean bibliography prevents one from easily accepting any text as static data to be mined. Bibliographers work not with direct linguistic emanations from an author's mind, but rather with recorded texts in manuscript or print form, which can only be properly understood in the context of a model of their material transmission.

In what follows, we examine a selection of editing projects from the history of Shakespeare publishing and explore both how existing models guided editors in their work and what new models they constructed as a consequence of their labor. To begin, we examine the modeling of Shakespeare's plays as an exploratory function, and draw comparisons between the dramaturgical practice of imagining possibilities for performance, particularly through the use of physical aids, and the practice of data

\footnotetext{
the Bible, and the Form of the Book: Contested Scriptures, ed. Travis DeCook and Alan Galey (New York: Routledge, 2012), 25-39.

${ }^{8}$ For similar analyses of other kinds of editions and digital resources, see Sarah Werner, "Digital First Folios," in The Cambridge Companion to Shakespeare's First Folio, ed. Emma Smith (Cambridge: Cambridge UP, 2016), 170-84; Bonnie Mak, "Archaeology of a Digitization," Journal of the American Society of Information Science and Technology 65.8 (2014): 1515-26; and Whitney Anne Trettien, "A Deep History of Electronic Textuality: The Case of English Reprints Jhon Milton Areopagitica," Digital Humanities Quarterly 7.1 (2013), http://www.digitalhumanities.org/dhq/vol/7/1/000150/000150.html.

${ }^{9}$ See the authors' white paper, "Textual Apparatus and Digital Labour in the Arden 4 Shakespeare Editions" (2016), http://hdl.handle.net/1807/76923.
} 
modeling in the digital humanities. From that we turn to historical examples of editors who were forced to confront an existing model of the text, and who, through their struggles, illuminate the sometimes invisible infrastructures in which editorial work takes place. Finally, we turn to the idea of textual scaffolding - the elements of the text that allow it to function but are not considered to be inherently authorial-and the question of how one particular aspect of this scaffolding has evolved over the history of Shakespeare editing. As we shall see, a digital model is not merely a representation of something but rather, in the words of computing historian Michael Mahoney, an "operative representation" with moving parts-literal and figurative-that call for manipulation, conjecture, and, as the next section will suggest, play. ${ }^{10}$

\section{Shakespeare and the Practice of Modeling}

As the second epigraph suggests, modeling is a promising foundation for forms of humanities computing that do not merely apply digital tools to humanities research questions unidirectionally but also apply humanistic ways of thinking within computing practices such as programming, data modeling, and interface design-a form of computing "that is of as well as in the humanities," as McCarty puts it. McCarty's deliberate and mindful use of the term model-or, more aptly, its gerundive form, modeling - offers a promising alternative to the idea that the digital humanities necessarily entail instrumentalism, positivism, or solutionism. In his attempt to articulate forms of humanities computing worthy of the name, McCarty describes modeling as a practice that sounds surprisingly akin to performance: "Computational models, however finely perfected, are better understood as temporary states in a process of coming to know rather than fixed structures of knowledge. . . Although efficient access to data is an essential function of computing, the greater potential is for computers as modelling machines, not knowledge jukeboxes. To think of them as only the latter is profoundly to misunderstand human knowledge."11 It is not difficult to make the imaginative leap from McCarty's influential definition of modeling in humanities computing, above, to Shakespearean performance. Dramaturgy itself might just as easily be described as "a continual process of coming to know by manipulating representations," but with dramatic performance as its outcome. The dominant explanatory metaphors for computers often take the form of analytical engines or content-delivery platforms (i.e., McCarty's "knowledge jukeboxes"), but to think of computers as stages is to invite historical questions about modeling as a practice native to the arts and humanities, and not limited to digital computing. To what extent does digital Shakespeare scholarship also involve-and require-modeling in McCarty's sense of the term?

Before we can answer that question, it is worth considering how and why the idea of modeling became so important in the digital humanities. As an imported scientific term, model carried a certain amount of semantic baggage long before it entered our present context. As Nelson Goodman complained in 1968, "Few terms are used in popular and scientific discourse more promiscuously than 'model.' A model is something to be admired or emulated, a pattern, a case in point, a type, a prototype, a

\footnotetext{
${ }^{10}$ Michael Sean Mahoney, "The Histories of Computing(s)," in Histories of Computing, ed. Thomas Haigh (Cambridge, MA: Harvard UP, 2011), 54-73, esp. 67.

${ }^{11}$ Willard McCarty, Humanities Computing (Basingstoke, UK: Palgrave Macmillan, 2005), 27.
} 
specimen, a mock-up, a mathematical description - almost anything from a naked blonde to a quadratic equation - and may bear to what it models almost any relation of symbolization." 12 Yet the term gains some precision through Goodman's distinction between an exemplary model (such as a developer's model house) and a denotative model (such as a car of a particular model). ${ }^{13}$ Clifford Geertz phrased the same distinction in terms more amenable to humanities computing by distinguishing between models for and models of. ${ }^{14}$ One might follow a model for building a house-as Lord Bardolph describes in the epigraph above-or one might create a model of the theater in which 2 Henry IV was first acted. Digital editing projects usually involve both types of modeling at different times, though the most interesting moments come when one cannot tell the difference. An XML-encoded scene that specifies entrances, exits, and simultaneous action may serve as a model for different acts of representation-such as an impromptu classroom staging-but also, at the same time, as an editor's or encoder's model of her interpretation of ambiguous, erroneous, or absent stage directions in the quarto or Folio texts. ${ }^{15}$

The point, either way, is that insight into our materials may result from the activity of modeling - if we do it well and have the right infrastructures to help. Digital humanities projects may or may not support the modeling of texts like Shakespeare's intelligently, depending on their editorial transparency and bibliographical precision (as we shall see below). But some in the field have developed theories and practices of modeling that marry digital technologies and techniques with the epistemologies of the humanities. Building on McCarty's work, Julia Flanders and Fotis Jannidis's 2015 white paper, "Knowledge Organization and Data Modeling in the Humanities," offers a lucid and comprehensive discussion of data modeling that outlines the concept's origins in computer science, as well as relevant distinctions such as the one between normative and exploratory data modeling (the latter being our concern here). ${ }^{16}$ Although the construction of data models for the purpose of exploring the nature of one's materialsas opposed to normalizing them for the sake of consistency-is by no means unique to the humanities, Flanders and Jannidis note that humanists rarely work with data derived from natural phenomena, but rather with constructed artifacts that have histories. As they conclude, "Data modeling in the humanities is always happening in the context of former attempts to model [specific and generic classes of objects].

\footnotetext{
${ }^{12}$ Nelson Goodman, Languages of Art: An Approach to a Theory of Symbols, 2nd ed. (Indianapolis, IN: Hackett, 1976), 171.

${ }^{13}$ Goodman, Languages of Art, 171-72.

${ }^{14}$ Clifford Geertz, The Interpretation of Cultures: Selected Essays (London: Fontana Press, 1993), 93.

${ }^{15}$ This is why the ubiquitous Moby Shakespeare and Project Gutenberg texts should never be mistaken as straightforward data for mining; they are always someone's model of Shakespeare, sometimes with the serial numbers filed off. See Andrew Murphy's criticism of this tendency in two reviews of digital Shakespeare projects: Review of Electric Shakespeares, The Arden Shakespeare CD ROM, in Computers and the Humanities 32.5 (1998): 411-20; and in "Shakespeare Goes Digital: Three Open Internet Editions," Shakespeare Quarterly 61.3 (2010): 401-14. See also Alan Galey's chapter "Data and the Ghosts of Materiality," in The Shakespearean Archive: Experiments in New Media from the Renaissance to Postmodernity (Cambridge: Cambridge UP, 2014), 236-70.

${ }^{16}$ Julia Flanders and Fotis Jannidis, "Knowledge Organization and Data Modeling in the Humanities" (2015), 5; white paper resulting from a workshop of the same title held at Brown University, Providence, RI, 14-16 March 2012, http:// www.wwp.northeastern.edu/outreach/conference/kodm2012/. See also Elena Pierazzo, Digital Scholarly Editing: Theories, Models and Methods (Farnham, UK: Ashgate, 2015).
} 
Therefore the history of attempts to describe these classes should be known and understood in the community, and indeed constitutes an important strand of expertise for those undertaking the modeling." They go on to emphasize a key point: "this history predates the introduction of digital tools," and "there is thus an important historiographical aspect to modeling." 17

What then is the history of modeling in Shakespeare? If one were to approach this as a question about data modeling, one might begin with the history of digital markup systems such as XML, SGML, and even older digital technologies as they have been used in the representation of Shakespeare's texts. However, Shakespeare's theatrical history and bibliographical history alike mean that the field draws from other, more tactile traditions of modeling. On the book history side, an example of physical model-making similar to that of theatrical practitioners is Peter W. M. Blayney's model of the building that housed the Three Pigeons bookshop in St. Paul's Churchyard, which he built with removable layers to demonstrate the (partly conjectural) space in which a typical London bookshop did business. ${ }^{18}$ Building on this work, the Virtual St. Paul's Cathedral Project offers a digital model of the cathedral and its surrounds as both a digital and acoustic space. ${ }^{19}$ Both projects show the value of making three-dimensional models of historical materials (in Geertz's sense) to understand relationships that may not be apparent through narrative description or two-dimensional mapping.

Just as historians have made tactile models of the spaces where sermons were heard and books were sold at St. Paul's, so do bibliographers make abstract models for analyzing the construction of books themselves. For example, one of the most important essays dealing with the bibliographical description of copies of the First Folio is tellingly titled "A Model for Describing Shakespeare First Folios." ${ }^{20}$ In this work, Anthony James West performs a bibliographical equivalent of the mapping mentioned above. He sets parameters for accurate description of many copies of the same book, which must also account for a greater degree of heterogeneity among copies than the concept of ideal copy - inherited from older modes of descriptive bibliography-could sustain. ${ }^{21}$ West was not merely setting terms for descriptive metadata but also creating a descriptive model flexible enough to account for the complex materiality of First Folios: many contain sheets in variant states or with inking errors; others have been broken up and used to perfect other copies; and some may yet remain undiscovered and in unknown condition.

Accounting for the unknown is a hallmark of modeling, yet so is precision in articulating and operationalizing the known. That fine balance is most apparent in West's treatment of the Folio's collation formula, which he reprints in its three authoritative versions, W. W. Greg's, Charlton Hinman's, and Blayney's (the latter shown here):

\footnotetext{
${ }^{17}$ Flanders and Jannidis, “Knowledge Organization,” 16.

${ }^{18}$ When lecturing on the research he published in The Bookshops in Paul's Cross Churchyard, Blayney employed this model to illustrate the use of the interior space; see Peter W. M. Blayney, The Bookshops in Paul's Cross Churchyard, Occasional Papers of the Bibliographic Society, no. 5 (London: The Bibliographical Society, 1990).

${ }^{19}$ See the Virtual St. Paul's Cathedral Project website at https://vpcp.chass.ncsu.edu/.

${ }^{20}$ Anthony James West, "A Model for Describing Shakespeare First Folios, with Descriptions of Selected Copies," The Library, 6th ser., 21.1 (1999): 1-49. For the model's application, see West, The Shakespeare First Folio: A New Worldwide Census of First Folios (Oxford: Oxford UP, 2003).

${ }^{21}$ West, "A Model," 3.
} 


$$
\begin{aligned}
& 2^{\circ}:{ }^{\pi} A^{6}\left({ }^{\pi} \mathrm{A} 1+1,{ }^{\pi} \mathrm{A} 5+1: 2\right) ; \mathrm{A}-\mathrm{Bb}^{6} \mathrm{Cc}^{2} ; \mathrm{a}-\mathrm{g}^{6} \chi_{\mathrm{gg}} \mathrm{gg}^{8} \mathrm{~h}-\mathrm{v}^{6} \mathrm{x}^{4} ;{ }^{\prime} \mathrm{gg} 3: 4^{\prime}\left( \pm^{\prime} g g 3^{\prime}\right) \\
& \mathbb{I}-\mathbb{I} \mathbb{I}^{6} \text { 3प1 aa-ff' }{ }^{6} \mathrm{gg}^{2} \mathrm{Gg} \mathrm{g}^{6} \mathrm{hh}^{6} \mathrm{kk}-3 \mathrm{~b}^{6}
\end{aligned}
$$

West reprints the three different formulas, but settles on Blayney's as the one that guides his own descriptive model. ${ }^{22}$ In doing so, he demonstrates that a collation formula is itself a kind of model: the collation formula maps the book's physical assembly of printed sheets, not its contents, and whenever there is more than one way to assemble a book (correctly or incorrectly), there is more than one way to write the formula to express the form of the ideal copy. As Sarah Werner notes, the part of the formula that describes the Folio's preliminaries $-{ }^{\pi} \mathrm{A}^{6}\left({ }^{\pi} \mathrm{A} 1+1,{ }^{\pi} \mathrm{A} 5+1: 2\right)$ - is especially sensitive to conjecture because different copies of the Folio have been assembled in different ways that affect the sequence of pages. ${ }^{23}$ After using this part of the collation formula to specify the differences between specific copies, Werner notes that "it is possible to compare the First Folio preliminaries in aggregate this way because bibliographers have developed a method for describing the physical properties of printed books and have come to agree on a standard reference system for noting the order of the ideal copy of the First Folio." ${ }^{24}$ Both West's and Werner's uses of the Folio's collation formula illustrate its functionality as a model that enables both precision and conjecture, much like the corresponding paper-folding exercises often used in bibliography classes to teach students how, for example, a folio in sixes or a quarto may be put together. In bibliographical work, one may construct a model out of paper or out of symbols; the point is to create an operative representation that rewards intelligent questioning.

Thus, a model may be physical or abstract, but theatrical modeling usually involves a measure of both. One of the most well-known makers of theatrical models was Edward Gordon Craig, son of Shakespearean actor Ellen Terry and a talented scenic designer, illustrator, and performance theorist in his own right. Prior to his most famous production, the modernist Hamlet he designed for co-director Constantin Stanislavski's Moscow Art Theatre in 1911, Craig had developed his modernist stage designs and moveable screens with the help of small, manipulable scale models. As Peter Holland describes, "These hinged panels were intended to provide thousands of possibilities from a single design," and the manipulability of the models was intended to be translatable into the full-scale screens used in production. ${ }^{25}$

Yet as Craig's son recalls in his memoir, Craig "soon found that he needed figures in order to give an idea of scale to his scenes, and set to work, cutting them in bas-relief from very thin planks of wood." ${ }^{26}$ Realism was evidently not Craig's aim with these figures, and yet, as his son relates, "some of them could be manipulated to give very slight movements, such as the slow raising of a head or hand." ${ }^{27}$ Indeed, as Christopher Innes describes, Craig's representational choices with what became known

\footnotetext{
${ }^{22}$ West, "A Model," 8.

${ }^{23}$ Depending on how the gatherings in a given copy of the Folio were assembled, one might turn the "Catalogue" leaf to see the first page of The Tempest, or one might see Leonard Digges's memorial poemoddly separated from the other prefatory poems-and then a list of actors before reaching The Tempest. For explanations of these and other permutations, see Werner, "Digital First Folios," $179-81$.

${ }^{24}$ Werner, "Digital First Folios," 180.

${ }^{25}$ Peter Holland, introduction to Edward Gordon Craig, Index to the Story of My Days (Cambridge: Cambridge UP, 1981), xviii.

${ }^{26}$ Edward Craig, Gordon Craig: The Story of His Life (London: Victor Gollancz, 1968), 239.

${ }^{27}$ Craig, Gordon Craig, 239-40.
} 


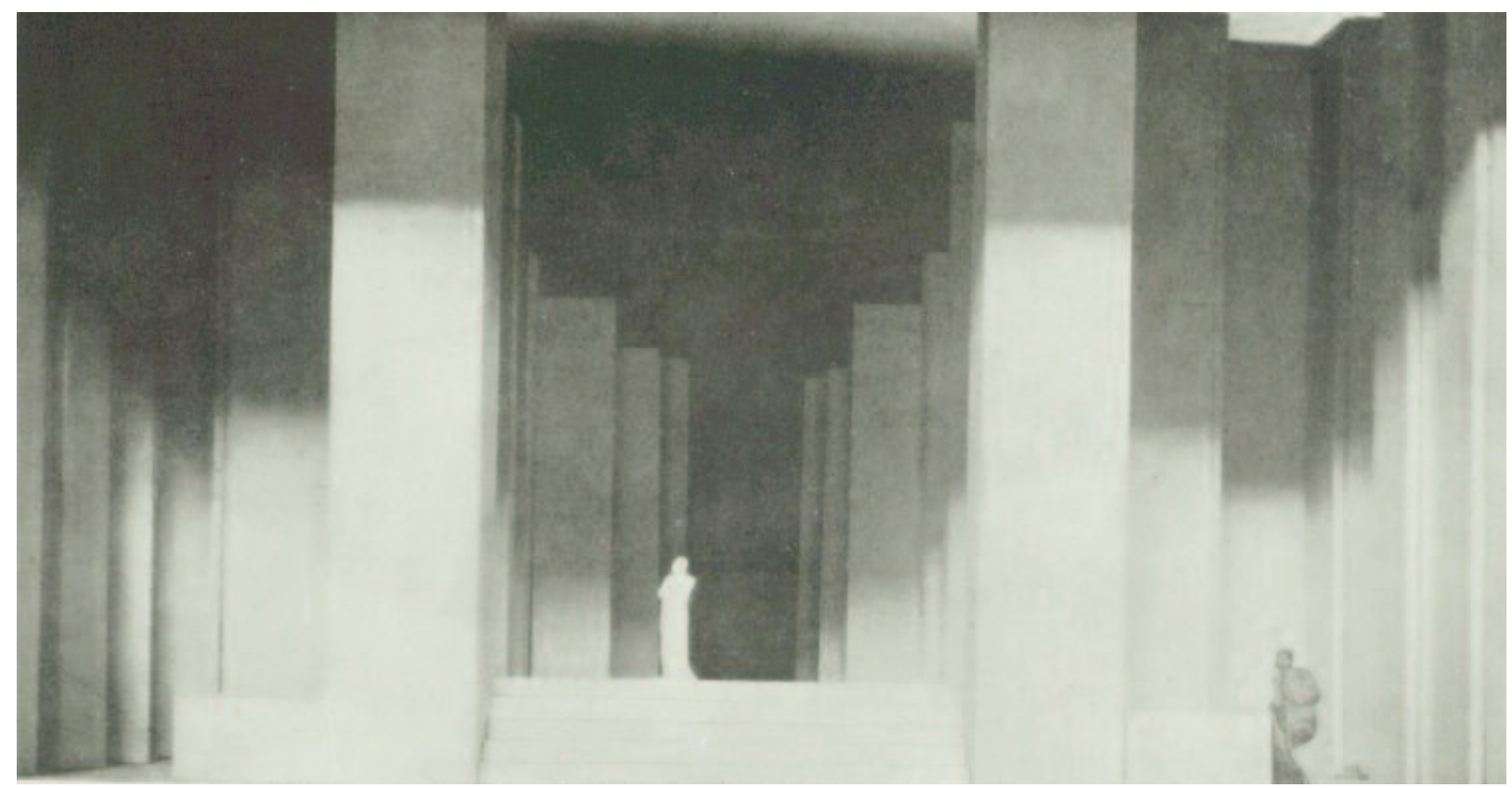

Figure 1. Photograph of Edward Gordon Craig's model for the final act of Hamlet, as shown in Towards a New Theatre: Forty Designs for Stage Screens with Critical Notes by the Inventor (London: J. M. Dent, 1913), plate facing p. 85. Image reproduced by permission of the Thomas Fisher Rare Book Library, University of Toronto.

as his Black Figures resulted in "a wide variety of clearly defined characters and dramatic poses. .. . The earlier Black Figures-for 'a Greek drama'—represent idealized actors. Later ones show actors portraying symbolic archetypes, such as 'Fear' and 'Lust,' whereas the series for Hamlet is individualized." 28 These were models for in a very real sense: the cast of the Moscow Hamlet actually used these figures as guides to the production (figure 1).

Yet apparently Craig's Black Figures also functioned for him as models of, as Innes suggests: "Even in the photographs recording configurations of screens that were not designed for any particular play, the clearly dramatic groupings of many of these figures and the use of sometimes ten or more in a single scene indicate the intended relationship between the screens and conventional theater." ${ }^{29}$ A contemporary of Craig's who seemed to appreciate this aspect of modeling was W. B. Yeats, who received from Craig a model stage with moveable screens for use in productions at the Abbey Theatre in Dublin. ${ }^{30}$ Yeats describes Craig's gift in terms that evoke many present-day aspirations for digital humanities tools:

All summer I have been playing with a little model, where there is a scene capable of endless transformation, of the expression of every mood that does not require a photographic reality.... Henceforth, I can all but produce my play as I write it, moving hither and thither little figures of

\footnotetext{
${ }^{28}$ Christopher Innes, Edward Gordon Craig (Cambridge UP, 1983), 141.

${ }^{29}$ Innes, Edward Gordon Craig, 141.

${ }^{30}$ Craig, Gordon Craig, 254-55.
} 
cardboard through gay or solemn light and shade, allowing the scene to give the words and the words the scene. I am very grateful, for he has ... given me forms and lights upon which I can play as upon some stringed instrument. ${ }^{31}$

In contrast to the world of "photographic reality," the interplay of verbs and nouns in Yeats's brief description gives a sense of the model's manipulability, culminating in an instrumental metaphor that captures the value of modeling in the arts far more aptly than metaphors of tools or workbenches.

We will return to Craig again below, but for now his experiments with theatrical scale models serve to illustrate a form of modeling that has its roots in the arts, not computer science, and yet forms part of the historiography of pre-digital modeling posited by Flanders and Jannidis. Indeed, the accounts of Craig and Yeats bear out McCarty's argument that a philosophy of modeling would be identifiable through several attributes that should emerge in its practice. Those attributes include "the manipulatory essence of modelling, with its connotation of embodied action, physically or metaphorically; the mediating role and ternary relationship modelling establishes between knower and known; the directed, vector-like engagement of the inquirer's attention, through the model he or she has made to the object of study; and the model's consequent function as an artificial agent of perception and instrument of thought." 32 Compare these attributes to the accounts quoted above, especially Yeats's point that the model allows "the scene to give the words and the words the scene," which mirrors McCarty's point about vectoring one's attention through a model to an object of study.

What, then, does modeling in these senses have to do with Shakespeare editing and its digital infrastructures? As the present authors and others in the digital humanities have argued, textual scholarship and text encoding are practices that, when combined, can help us see the mutual illumination that Shakespeare's texts and their remediation can shed on each other..$^{33}$ Models are constructed spaces within which that illumination can happen, as the play of light and shadow falls on those elements we choose to include and manipulate.

An example of digital Shakespearean modeling comparable to Craig's arose in the practice of FDT designers and encoders Michael Poston and Rebecca Niles. As they translated the Folger Shakespeare editions from print to electronic text, which required the addition of XML markup to specify entrances, exits, and other stage directions, they were confronted with questions about the presence or absence of minor characters onstage, especially the servants who populate Shakespeare's plays in functional yet (usually) forgettable roles. Regularized printed editions can make it easy to forget or silently overlook characters who are present but not active, but theatrical performance and digital modeling alike force their practitioners to make explicit the possibilities that the text leaves tacit. In the theater, actors are either present onstage or not, and in a small cast their presence in any given scene will almost certainly register as a constraint in any part-doubling scheme.

\footnotetext{
${ }^{31}$ W. B. Yeats, "The Tragic Theatre," The Mask 3.4-6 (1910): 81; see also Denis Bablet, The Theatre of Edward Gordon Craig, trans. Daphne Woodward (London: Methuen, 1981), 129.

${ }^{32}$ McCarty, Humanities Computing, 38.

${ }^{33}$ See Alan Galey, "Encoding as Editing as Reading," in Shakespeare and Textual Studies, ed. M. J. Kidnie and Sonia Massai (Cambridge: Cambridge UP, 2015), 196-211; and Rebecca Niles and MichaelPoston, "ReModeling theEdition: Creating the Corpus of FolgerDigitalTexts," in Early Modern Studies after the Digital Turn (Tempe, AZ: ACMRS Publications, 2016).
} 


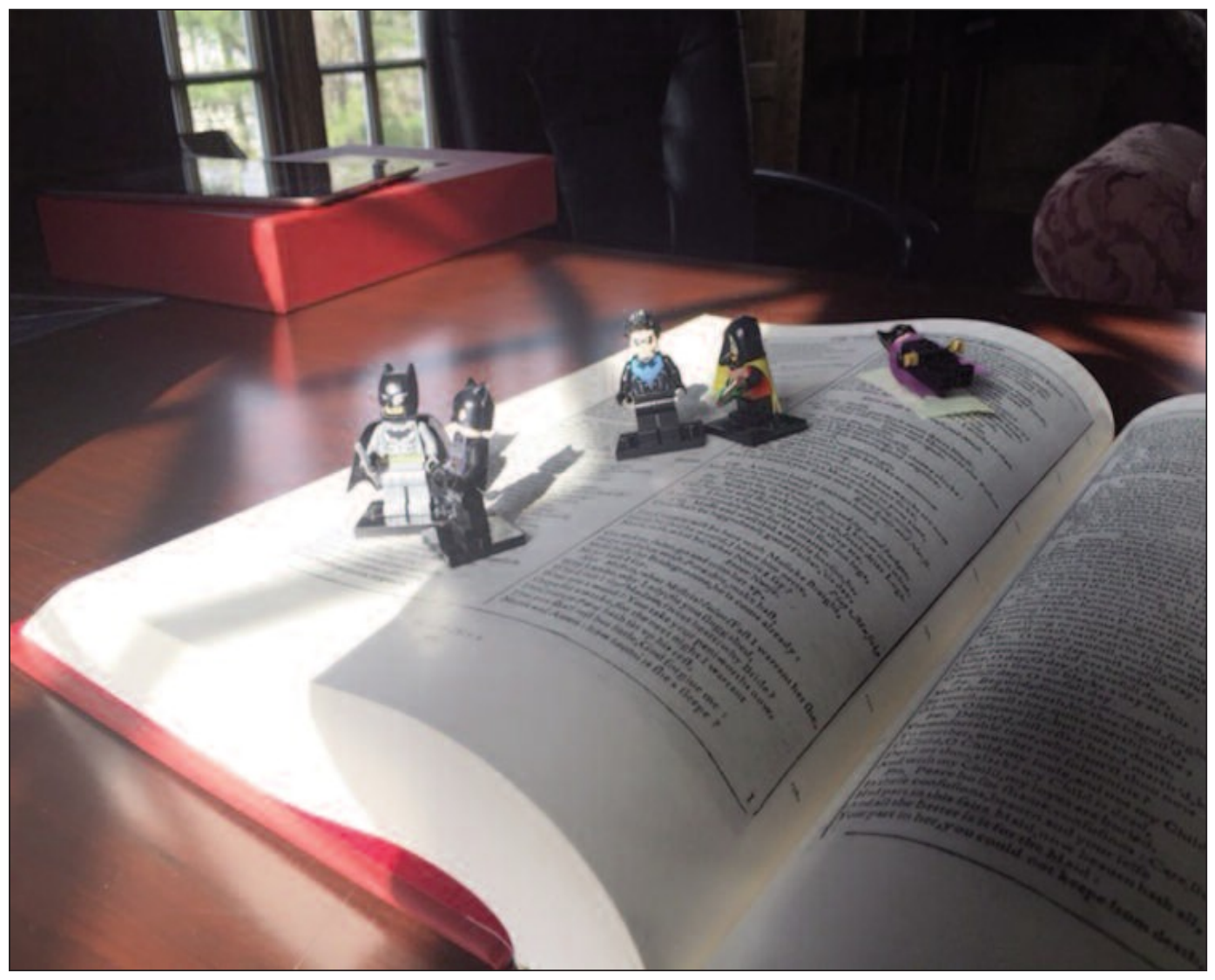

Figure 2. Romeo and Juliet's Act 4, scene 4, blocked using Lego Batman characters to determine how to encode entrances and exits. Image courtesy of Michael Poston.

Like Craig with his Black Figures on his model stages, Niles and Poston made use of Lego figures to act out ambiguities in stage directions. ${ }^{34}$ As shown in figure 2, a ready supply of mini-figures from Lego's Batman collection depict the final lines of Act 4, scene 4 of Romeo and Juliet. In this scene Lord Capulet (Batman) is instructing the Nurse (Catwoman) to prepare Juliet (Batgirl) for her wedding to Paris. In the scene to follow, the Nurse will discover Juliet's apparent death. Using objects at hand to model scenes from the Folger Shakespeare Library editions allowed Niles and Poston to identify and at times resolve stage directions that were ambiguous or otherwise difficult to encode using the syntax of XML and the semantic structure of FDT. Tracking these stage directions with models made it explicit that several servingmen (represented here by Nightwing and Robin) enter the scene but do not exit. This fact is perhaps not crucial to reading and understanding the scene-as readers supply missing information and rationalize inconsistencies as a matter of course-but it is necessary to address in order to create valid code, as it would be in order to stage the play in live performance. Modeling the entrances and exits through to the end of the act also made clear that

\footnotetext{
${ }^{34}$ For a more detailed discussion of Lego as an example of a modeling technology with relevance to digital text encoding, see Wendell Piez," On Data Modeling in the Humanities: Three Questions and One Experiment," keynote lecture for the "Knowledge Organization and Data Modeling in the Humanities" workshop (available online; see n. 16).
} 
Juliet is never given an explicit exit, forcing Niles and Poston either to emend the text silently (by encoding an exit for the character where none exists in the text of the original Folger edition) or to imagine a possible staging in which Juliet remains onstage at the end of the act-as indeed some directors do when staging this play. In this instance, the model stands in not only for the activities depicted by the text but also for the constraints and affordances of the medium into which the text is being translated.

Little about this kind of modeling exercise may seem new to dramaturges, performance critics, or course instructors who lead students studying Shakespeare through blocking exercises. However, that is exactly the point: text encoding and data modeling, when approached the right way, are continuous with these more familiar practices. The link that Flanders and Jannidis suggest between digital and pre-digital forms of modeling is our focus in the rest of this essay, which we explore through the forms of editorial infrastructures and textual scaffolding that pre-digital Shakespeare editors have employed. The manipulable "hypothetical constructs" that McCarty describes are not merely abstractions in the account that follows; they become materialized in editions, but perhaps even more so in the paper-and-ink (and scissorsand-glue) infrastructures that pre-digital editors have built to support their work. The interplay of materiality and abstraction - and of constraint and aspiration-is key to modeling, as Lord Bardolph makes clear later in his warning to the Archbishop of York and the other rebels:

We fortify in paper and in figures,

Using the names of men instead of men;

Like one that draws the model of a house

Beyond his power to build it.

$$
\text { (2 Henry IV, 1.3.58-61) }
$$

Had the rebels heeded this lesson about modeling more carefully at the time, things might have gone differently for them at Gaultres later in the play. Drawing houses beyond our power to build could be an apt description for many digital humanities projects, but as Shakespeare reminds us, the work usually begins with paper and the naming of entities. It is to that work that we turn in the next section.

\section{Fortifying in Paper: Staunton, Furness, and Craig}

The term editorial infrastructures likely conjures up twenty-first century images of XML files, Text Encoding Initiative (TEI) schemas, digitization software and hardware, grant applications, advisory boards, research assistants and postdocs, and project management practices distilled into PowerPoint bullets. These are the contours of the world in which many Shakespeare editors do their work since the mainstream takeup of the digital humanities. yet the infrastructures with which Shakespeare editors worked in the past were largely based on technologies such as paper, print, manuscript, and (after the mid-nineteenth century) photography. Although the technologies have obviously changed since the nineteenth century, it is possible to combine the perspective of a book historian and a text encoder to understand the continuities in Shakespeare editing that connect across generations of scholars. To regard a print edition as a designed object, with its information architecture expressed through the constraints and affordances of its medium, is to recognize that computing and 


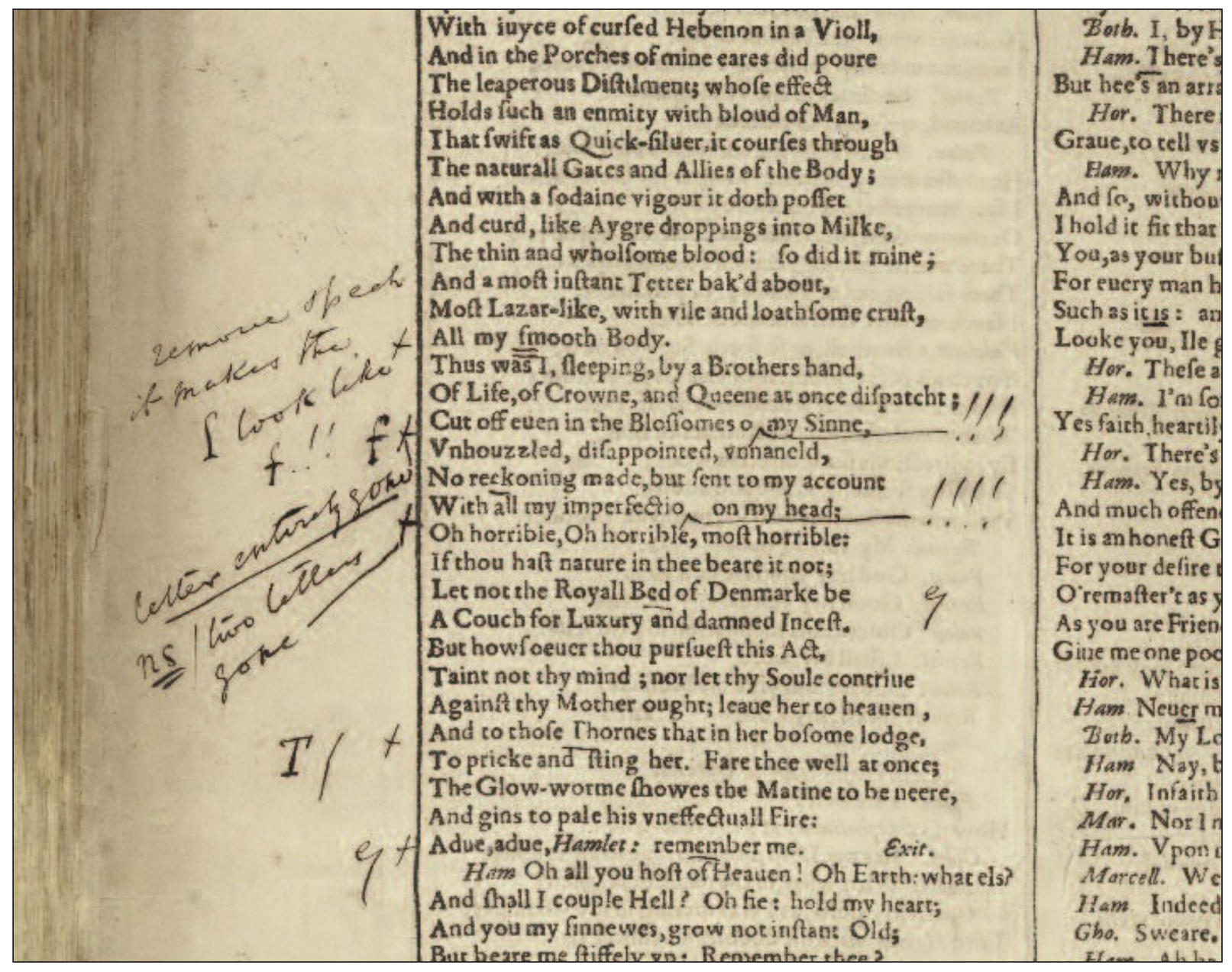

Figure 3. Staunton's corrections in his proof-copy of his photolithographic First Folio facsimile, sig. oo1v in Hamlet (see n. 36). Used by permission of the Folger Shakespeare Library under a Creative Commons Attribution-ShareAlike 4.0 International License.

information management are not exclusively digital practices, or exclusive to modern digital technologies. ${ }^{35}$ The three examples below provide glimpses over the shoulders of working editors and book designers, as it were, but more importantly, they also reveal Shakespeareans wrestling with the same kinds of modeling questions that digital humanists face today.

In the 1860s, the noted chess player and Shakespeare editor Howard Staunton was preparing his facsimile edition of the First Folio, which would introduce many Shakespeare readers to the idea of photographic reproduction of old books. One of the Folger copies of the 1866 facsimile happens to be Staunton's own proof copy, prepared by the printer Day and Son so that Staunton could check the quality of the reproductions against the original (figure 3). ${ }^{36}$ In his numerous annotated queries,

${ }^{35}$ The following three paragraphs are revised and expanded from Alan Galey's chapter "Reading Shakespeare through Media Archaeology," in Shakespeare in Our Time: A Shakespeare Association of America Collection, ed. Dympna Callaghan and Suzanne Gossett (London: Bloomsbury Arden Shakespeare, 2016), 103-6.

${ }^{36}$ H. Staunton, [ed.], The First Collected Edition of the Dramatic Works of William Shakespeare: A Reproduction 
instructions, expostulations, and other material traces of textual labor, Staunton inadvertently left a record of his own detailed reading of a new media artifact, as he painstakingly evaluates the capacity of one new medium (photography) to remediate another (early modern print). Photographic facsimiles became part of the technological infrastructure of Shakespeare editing after their introduction in the mid-nineteenth century, and yet their status as edited texts themselves has long been a matter of concern in Shakespearean textual scholarship. In the surviving traces of Staunton's proofreading, we can see how an editor's labor to produce an early photographic Shakespeare facsimile anticipates one of the most basic tasks in digital text encoding: to establish parameters for precision in the transcription of texts, often at the level of encoding the letters, numbers, and other symbols that appear in text.

The work of proto-digital data modeling is evident in the patterns of Staunton's annotations, many of which seek to arrest the proliferation of meaning that occurs as text passes through the interfaces between old and new media. For example, throughout his proof corrections, Staunton struggles to keep long-s (f ) characters from becoming $\mathrm{f}$ 's, and vice versa, due to the inadvertent addition or omission of the tiniest of marks - an unavoidable hazard in the photolithographic process. In the example from the Ghost's speech to Hamlet shown in figure 3, one can see Staunton noting in the margin, with apparent frustration, "remove speck / it makes the f look like f!!" resulting in the misreading "All my fmooth Body." On lines just below he notes, with increasing exclamation marks, an " $\mathrm{f}$ " and " $\mathrm{n}$ " that did not register at all. Other, more frequent Staunton-isms among the proof corrections include "speck," "dot-i," and "clean out" (all visible, for example, on sig. P5v of the Comedies), as ink, dirt, paper, and meaning take on configurations just beyond his control.

When one pages through the entire proof copy of the Folio facsimile, Staunton's flurries of correction notes give the impression of a man frantically patching leaks, as though the medium of print cannot hold back the torrent of misreadings as the text interfaces with the newer media of camera lenses, photo-sensitive plates, and lithographic substrates. Perhaps the most telling annotation occurs next to what appears to be the Folio's misprinted line in The Merchant of Venice, "my affaires have mad: you wait" (figure 4), where Staunton asks, as if in a moment of existential angst, "What does this mean?" Here Staunton has encountered an $e$ that has become a colon either in the photolithography process or as the result of an inking error in his copy of the Folio. Staunton may well have wondered if he was dealing with a press-variant in his copy or possibly a consistently mis-set word that editors of the play had silently emended in all the modern editions Staunton had read. The possibilities for textual transformissions of this sort may not be infinite, but they are enough to drive any editor or encoder mad:

Those involved in Shakespearean new media projects today, especially the coders themselves, know the long hours, false starts, and conflicting imperatives that may leave their mark on the code, documentation, media files, data sets, and other layers of a digital project. Like Staunton, we have looked quizzically at prior layers of encoding and mediation and asked "What does this mean?" Staunton evidently found his answer, as his annotation indicates, but the question has a very different resonance and usefulness depending on whether one approaches the work as simple error correction or as modeling in a broader sense.

in Exact Fac-simile of the Famous First Folio, photo-lithography by R. W. Preston (London: Day and Son, 1866), Folger Shakespeare Library, shelfmark PR2752 1866n Sh.Col., copy 4. 


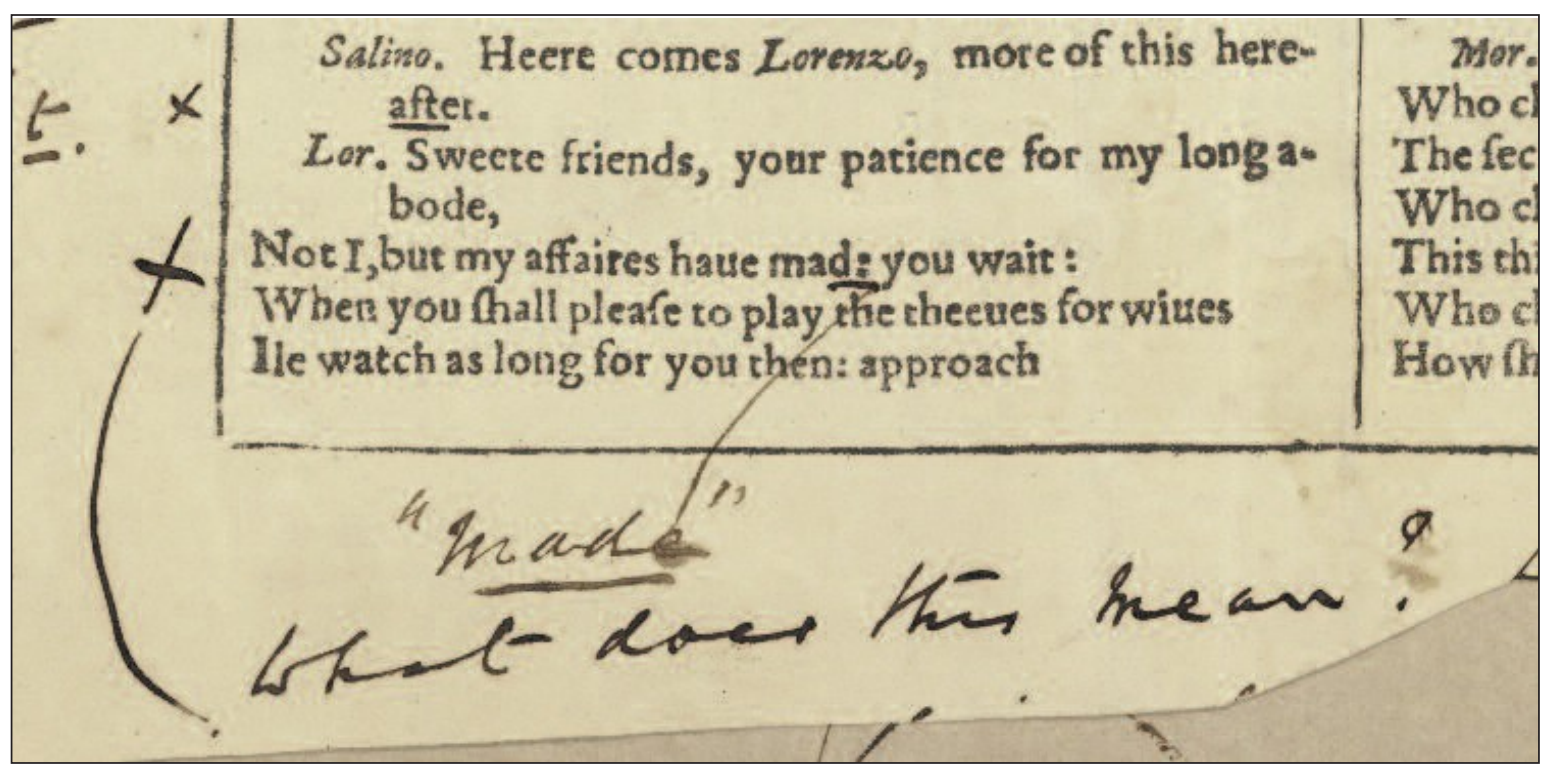

Figure 4. Staunton's corrections in his proof-copy of his photolithographic First Folio facsimile, sig. P1v in The Merchant of Venice (see. n. 36). Used by permission of the Folger Shakespeare Library under a Creative Commons Attribution-ShareAlike 4.0 International License.

Editorial modeling practices have also included the physical modification of books, sometimes with an eye to new kinds of book design. The working documents left behind by New Variorum Shakespeare editor Horace Howard Furness exemplify the techniques used by an editor working to construct a complex editorial model using the technology of his time. Figure 5 comes from Furness's copy of a volume of the Clark-Wright Cambridge edition of 1863-66, in which Furness compiled notes toward the textual apparatus for his first New Variorum edition, Romeo and Juliet, published in $1871 .^{37}$ Here we see material evidence of a Shakespeare editor at work, struggling with the history of textual variants and emendations (and conjectures) in a few lines from Romeo and Juliet, and building up an information architecture that would prompt new forms of book design for Shakespeare editions. Here, Furness has taken an existing edition-the Clark-Wright Cambridge being the most recent one with a detailed textual apparatus - and added his own exhaustive collation of other variants and emendations from prior editions. One can see in the printed notes that Clark and Wright had already done this to an extent, but theirs was a critical edition, not a variorum, so their inclusion of variants was selective. Furness, by contrast, aims for encyclopedism. If one looks closely, one can see well-known names from the eighteenth-century editorial tradition such as Capell, Rowe, Hanmer, Pope, and Theobald, but also relatively obscure names like Hudson, Singer, and Dyce from the nineteenth century. ${ }^{38}$ One may also see a good range of annotation techniques in use here, using different colors of ink and pencil, as well as cross-outs and paste-overs. This is an expert reader/editor at work, and one reading with pen, scissors, and paste.

\footnotetext{
${ }^{37}$ Philadelphia, University of Pennsylvania, Kislak Center for Special Collections, Rare Books and Manuscripts, Furness Family Papers, MS Col. 481, box 36, Romeo and Juliet, 66-67.

${ }^{38}$ On the contributions of Edward Capell, Nicholas Rowe, Thomas Hanmer, Alexander Pope, Lewis Theobald, Henry Norman Hudson, Samuel Weller Singer, and Alexander Dyce to the history of editing, see Murphy, Shakespeare in Print (see n. 6).
} 


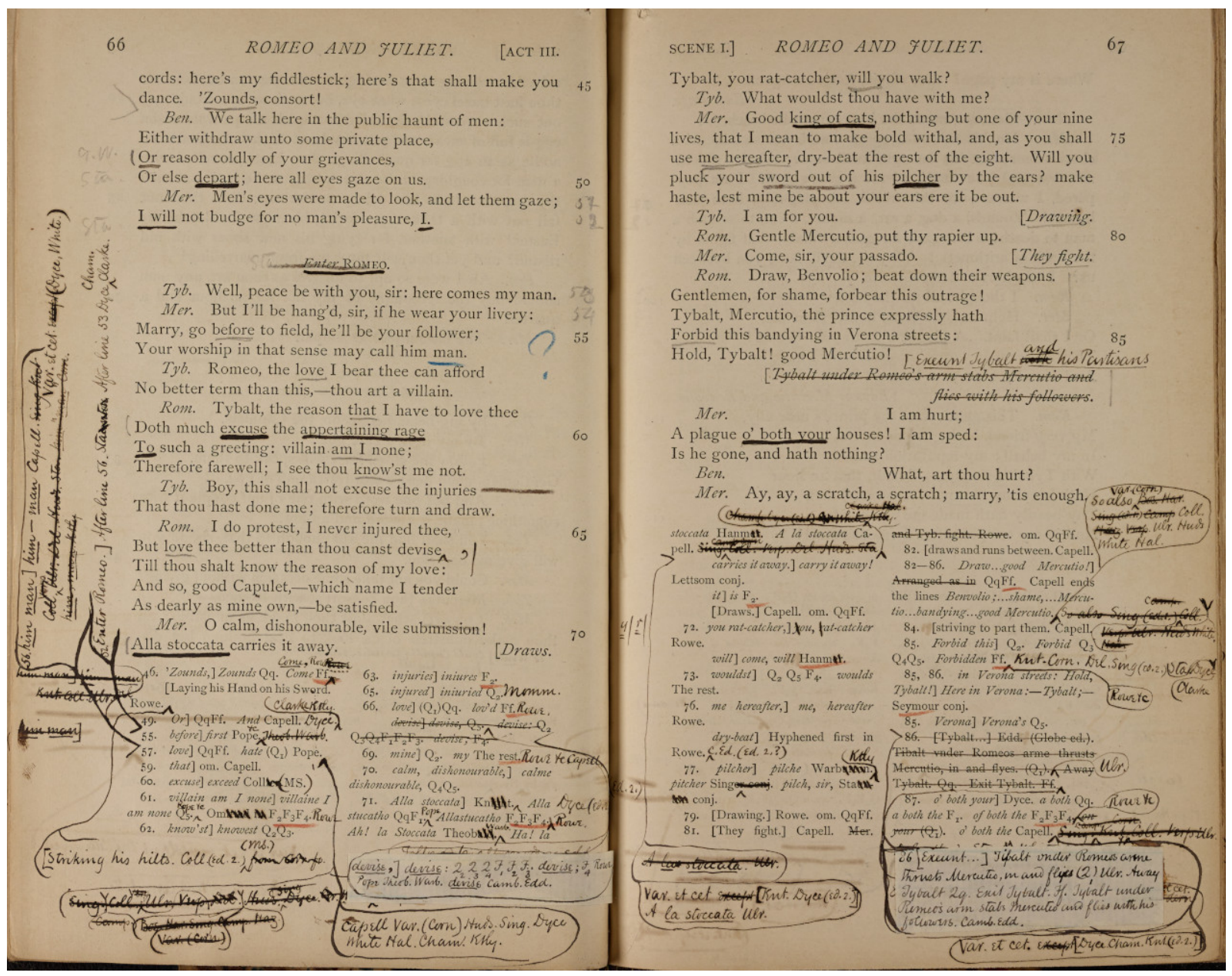

Figure 5. Horace Howard Furness's heavily annotated working copy of the Cambridge Romeo and Juliet (see n. 37). Reproduced by permission of the Kislak Center for Special Collections, Rare Books and Manuscripts, University of Pennsylvania. 


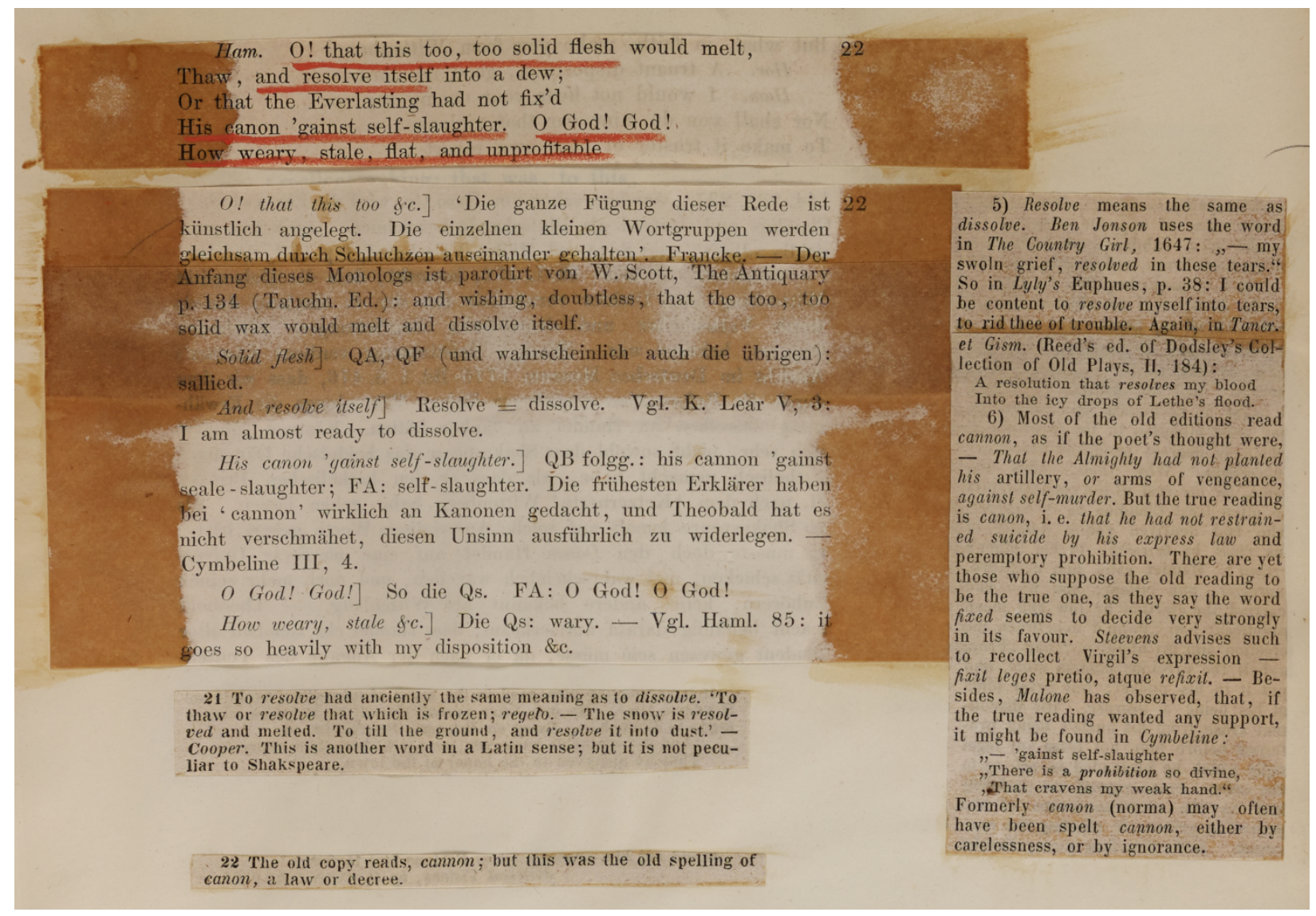

Figure 6. Horace Howard Furness's workbook for commentary for his New Variorum edition of Hamlet (see n. 39). Reproduced by permission of the Kislak Center for Special Collections, Rare Books and Manuscripts, University of Pennsylvania.

The annotations and paste-ins visible in figures 5 and 6 exemplify how readersmodern and early modern alike-often completed or extended the designs of printed books through their own material interventions. Figure 6 shows a typical page from Furness's large workbook for assembling commentary for his two-volume New Variorum Hamlet (1877), with lines of Shakespeare text accompanied by notes cut and pasted from other editions. ${ }^{39}$ Although the pages of the published New Variorum Shakespeare editions present their editors' synthesis of prior commentary, the intermediate stage in Furness's work shown in figure 6 reveals the work of aggregation that must happen first. This work could only be carried out in the context of material books, and yet Furness's own workbooks highlight the assembled and artifactual nature of editions, and link them to practices such as grangerizing, the Little Gidding gospel harmonies, and even William Burroughs's cut-ups. ${ }^{40}$

Considered from these various perspectives, Furness's variant-laden page shows the Shakespeare text in transit, passing through a range of media, publishing projects,

\footnotetext{
${ }^{39}$ Philadelphia, University of Pennsylvania, Kislak Center for Special Collections, Rare Books and Manuscripts, Furness Family Papers, MS Col. 481, box 21, Hamlet variorum manuscript, p. 74.

${ }^{40}$ On grangerizing, see Amanda Visconti, "Grangerizing," in Architectures of the Book, http://drc.usask.ca/projects/archbook/grangerizing.php. On the Little Gidding harmonies, see Whitney Trettien's website Cut/Copy/Paste: Toward a Digital Concordance Room, http://littlegiddingharmonies.org/.
} 
and book designs - and made to bear the weight of its histories along with it. ${ }^{41}$ As some of the most complex Shakespeare editions ever created, in terms of their typography and information architecture, the New Variorum Shakespeare editions could only have come into being through modeling processes that withdraw into the background of the pages of the finished editions but remain evident in the working documents of their editor.

For our final example we return to Edward Gordon Craig's theatrical models, but this time in their bibliographical connections via Craig's contributions to one of the twentieth century's greatest achievements in book design, the Cranach Press Hamlet, published in German and English, respectively, in 1928 and 1930. ${ }^{42}$ The Cranach Press was a private press founded in 1913 by Count Harry Kessler, a German aristocrat, writer, and patron of the arts, who had been inspired partly by Emery Walker, William Morris, and other members of the Arts and Crafts movement in England. ${ }^{43} \mathrm{~A}$ combination of design elements sets this edition apart. The text chosen is an edition based on the second quarto by J. Dover Wilson, thought at the time to be the version most proximate to Shakespeare's manuscripts. ${ }^{44}$ Flanking the Shakespeare text on either side are two of Hamlet's prose sources, a portion of the Historiae Danicae titled "The Life of Amleth" by the thirteenth-century author Saxo Grammaticus, and its sixteenthcentury retelling in the Histoires tragiques (1570) of French author François de Belleforest. Type was designed specifically for this book by Edward Johnston (also known for designing the iconic London Underground typefaces), who recreated a fifteenth-century typeface used by Gutenberg's contemporaries Johann Fust and Peter Schoeffer. ${ }^{45}$ Eric Gill, another collaborator of Kessler's, contributed some lettering, including two ornamental initials. This assembly of bookmaking expertise makes the Cranach Press Hamlet a tour de force of modern printing and scholarly editing, but the edition also references a specific performance through its illustrations, contributed by Craig in the form of wood engravings based on his designs for the 1911 Moscow Hamlet (discussed above). ${ }^{46}$ With his set-designer's eye, Craig created images that combine form, motion, lighting, and visual motifs to achieve a remarkable synthesis of page and stage (figures 7 and 8).

The book also registers its connections to Craig's earlier modeling practices in several of its illustrations, which derived from the Black Figures that Craig used in his model scenes (see figure 1). As Lindsey Newman describes, "These figures were cut in

${ }^{41}$ On the publishing and book-design contexts for Furness's Variorum project, see Murphy, Shakespeare in Print, 155-59; and Galey's chapter "The Archive and the Book: Information Architectures from Folio to Variorum," in The Shakespearean Archive, 78-117, esp. 94-106

${ }_{42}$ Die tragische Geschichte von Hamlet Prinzen von Daenemark (Weimar, Ger.: Cranach Press, 1928); and The tragedie of Hamlet, Prince of Denmarke (Weimar, Ger.: Cranach Press, 1930). For a detailed bibliographical account of the making of the Cranach Press Hamlet, see Lindsay Newman, "From Stage to Page: Hamlet with Edward Gordon Craig," in The Book as a Work of Art: The Cranach Press of Count Harry Kessler, ed. John Dieter Brinks (Laubach, Ger.: Triton Verlag, 2005), 126-45.

${ }^{43}$ See John Dreyfus, "The Cranach Press," in Into Print: Selected Writings on Printing History, Typography, and Book Production (London: British Library, 1994), 71-81.

${ }^{44}$ Kessler corresponded directly with Wilson about his belief that the second quarto of Hamlet, which formed the basis of his edition, was the version closest to Shakespeare's manuscripts; see Newman, "From Stage to Page," 132.

${ }^{45}$ On the typeface, see Sarah Werner, “Johnston's 'Hamlet' | Edward Johnston I 1929," Kern Your Enthusiasm, no. 4, Hilobrow.com, 4 August 2014, http: / hilobrow.com/2014/08/04/kern-your-enthusiasm-4/.

${ }^{46}$ See Meredith Mann, "From Stage to Page with the Cranach Press's Hamlet," New York Public Library blog, 14 November 2014, http://www.nypl.org/blog/2014/11/14/cranach-press-hamlet. 


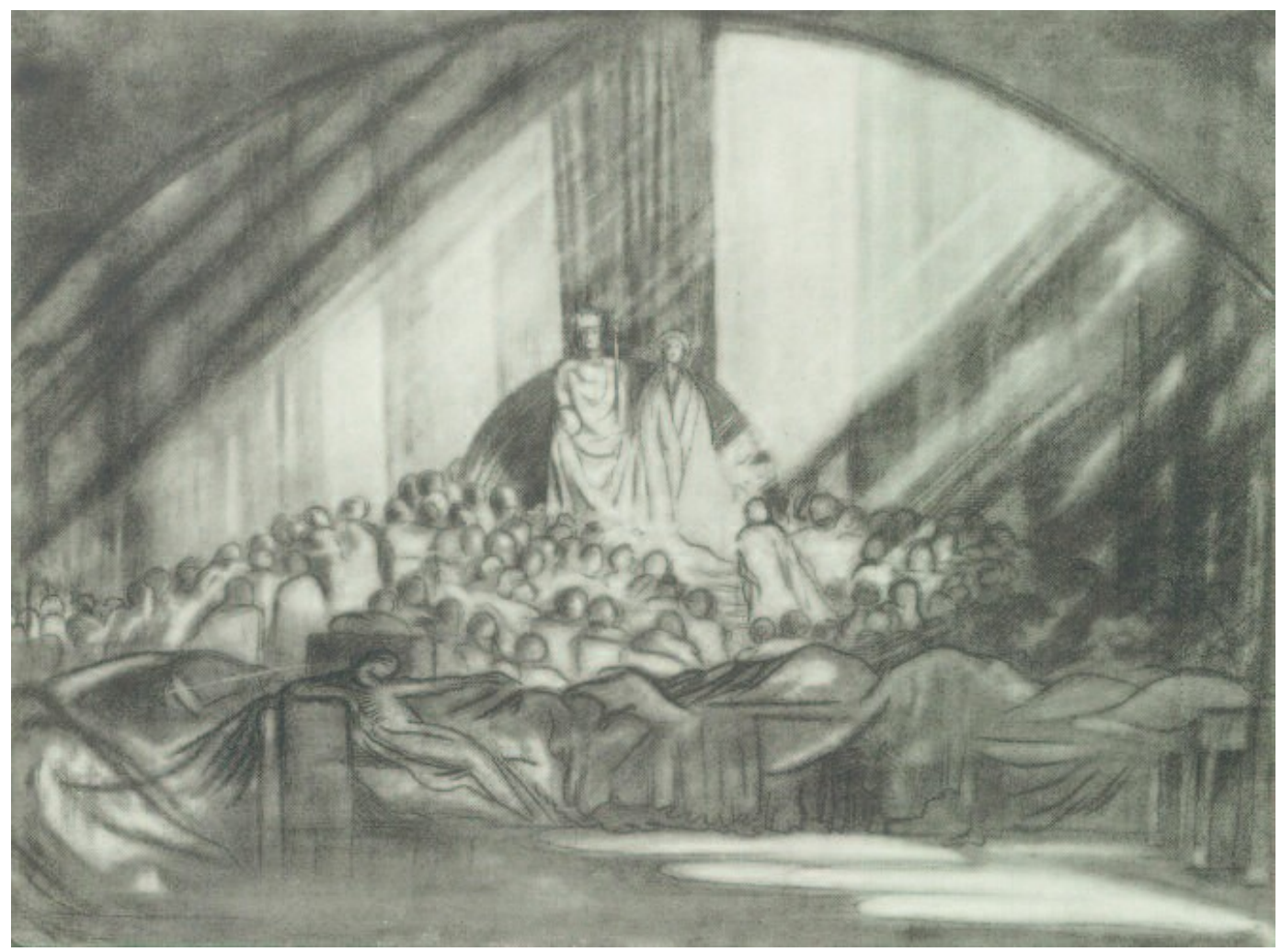

Figure 7. Edward Gordon Craig's illustration of Hamlet's Act 1, scene 2 for the 1911 Moscow Hamlet, reproduced in Towards a New Theatre: Forty Designs for Stage Screens with Critical Notes by the Inventor (London: J. M. Dent, 1913), plate facing p. 81. Image reproduced by permission of the Thomas Fisher Rare Book Library, University of Toronto.

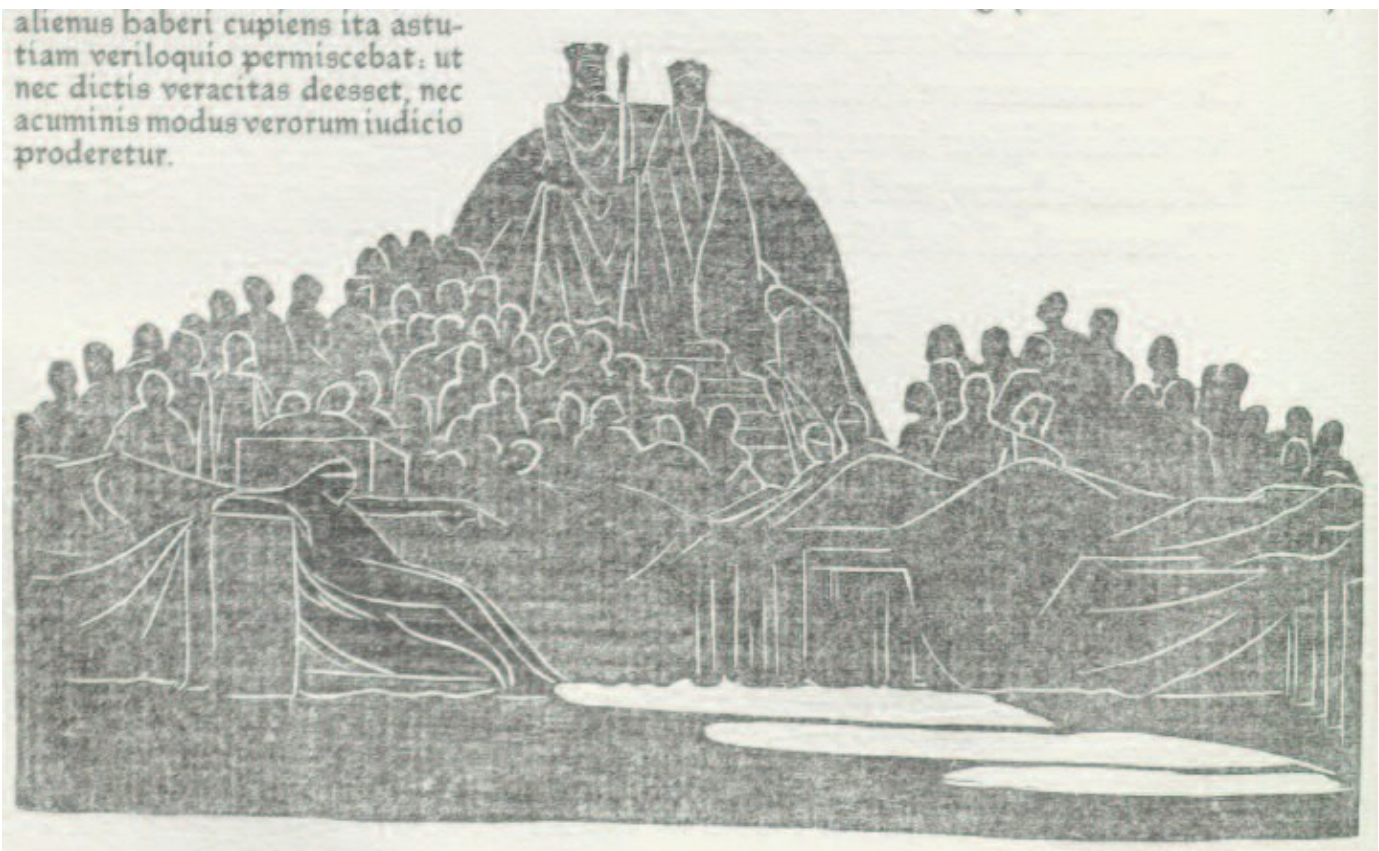

Figure 8. The same scene as a wood engraving for the Cranach Press Hamlet, p. 12 of the 1930 edition (see n. 42). Image reproduced by permission of the Thomas Fisher Rare Book Library, University of Toronto. 


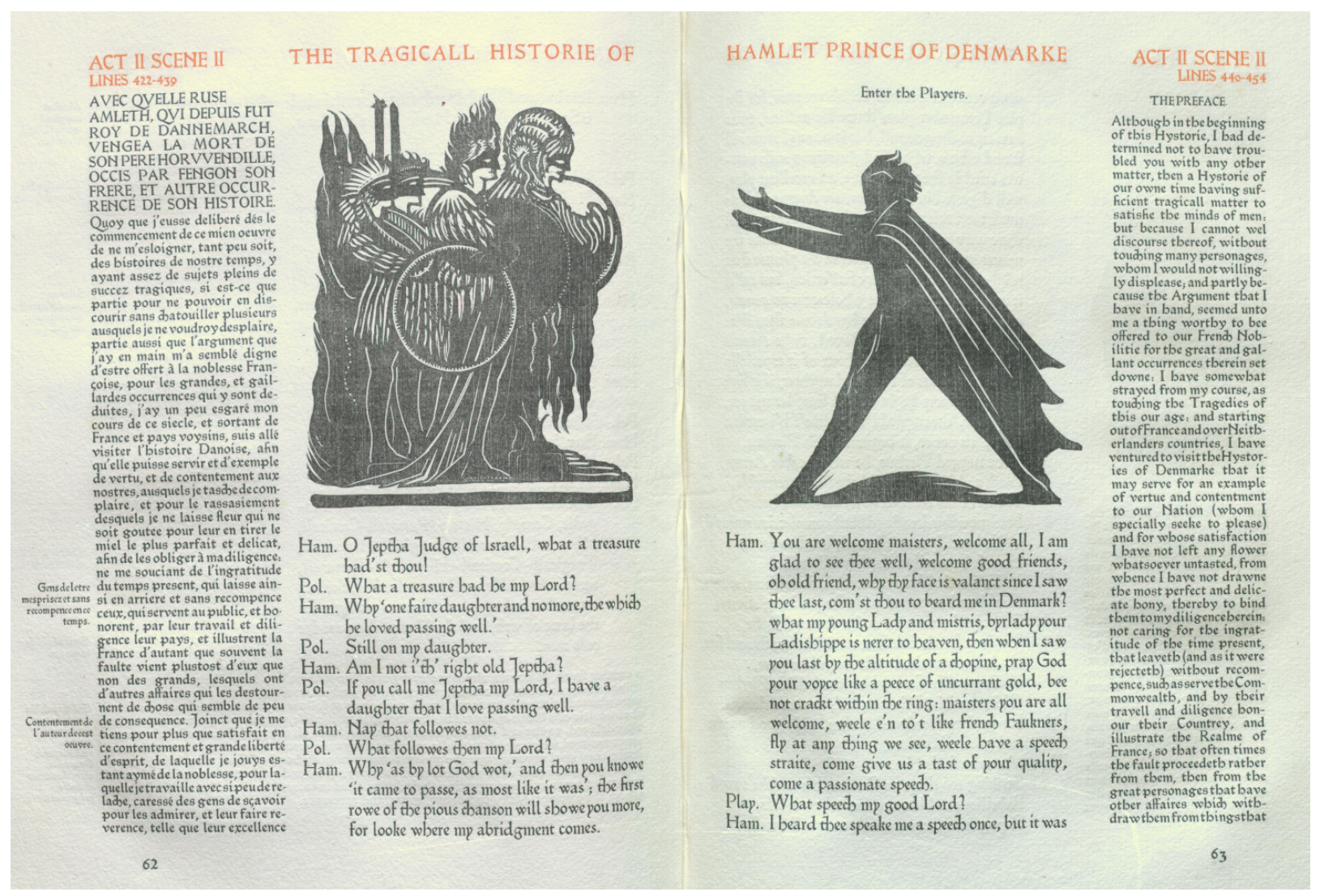

Figure 9. Edward Gordon Craig's Black Figures printed in the Cranach Press Hamlet, pp. 62-63 of the 1930 edition (see n. 42). Image reproduced by permission of the Thomas Fisher Rare Book Library, University of Toronto.

low relief with a fretsaw from soft wood and engraved with simple lines to suggest their personalities, action, and garments." ${ }^{47}$ Many of these figures were used as models for the 1911 Moscow Hamlet's design and costumes, but they also had a parallel existence in print, as Craig's son describes in his memoir: "One day, while [Craig] was making some prints from his ordinary boxwood blocks, he decided to ink the side of one of these figures, and he produced a print resembling a brass-rubbing from a church floor; this was so successful that he made prints from all the existing figures." 48 Kessler was impressed with these prints when he visited Craig in London in 1911, and nearly two decades later Craig's Black Figures were incorporated into the printing of the Cranach Press Hamlet (figure 9), traveling from stage to page in a very material sense. ${ }^{49}$

The Cranach Hamlet is a book that remembers a very specific performance-the 1911 Moscow production-but it is also an artifact that aspires to the condition of

${ }^{47}$ L. M. Newman, ed., The Correspondence of Edward Gordon Craig and Count Harry Kessler (Leeds, UK: W. S. Maney and Son for the Modern Humanities Research Association and the Institute of Germanic Studies, U of London, 1995), 82.

${ }^{48}$ Craig, Gordon Craig, 240.

${ }^{49}$ Newman notes that new figures had to be cut for printing in the Cranach Press Hamlet due to problems of scale or direction, though the "stage manager" figure was printed from Craig's original; Newman,

"From Stage to Page," 136. See also Newman's catalogue, Edward Gordon Craig Black Figures (Wellingsborough, UK: Christopher Skelton, 1989). 
performance. To its designers, it was a bibliographical performance: an enacted story that unfolds within the material and temporal form of the book. For digital

Shakespeareans, the Cranach Hamlet should represent not simply an artifact of the print culture that digital editions will allegedly supersede, but rather a collaborative multimedia experiment that attempts to forge links between textual and theatrical Shakespeare. Illustrations based on one of the vanguard modernist productions of Hamlet share the page with a playtext that embodied the radical new principles of New Bibliographical scholarly editing, and with two of the source texts that so fascinated Shakespeare's philologically minded eighteenth- and nineteenth-century editors-all rendered in a reading interface that represented the best of early twentieth-century typographic design. It is hard to imagine better inspiration for designers of digital Shakespeare apps and editions.

While Craig's Black Figures are the most literal examples of the impressions that models can leave in the editions that result from them, the material traces of editorial labor left behind by Furness and Staunton also highlight the modeling processes that editors engage in to varying degrees. In this light, the Staunton Folio facsimile, the New Variorum editions, and the Cranach Press Hamlet all become visible as layered sites of textual labor, not just static monuments. As artifacts, these books also depended on different kinds of textual infrastructures for their production-from Staunton's proof sheets to Furness's scrapbooks to Craig's multifunction Black Figures-and in turn joined a larger infrastructure of editions that make possible different experiences of Shakespeare texts in print. Not all models are so literal as Craig's, however, and the next section will consider more abstract forms of information architecture that digital editions have inherited from the past. As we shall see, digital text encoding for Shakespeare editions continues a form of data modeling that has been ongoing since at least the eighteenth century.

\section{The Evolution of Precision in Shakespeare's Editorial Interfaces}

Whether approaching a new edition of a Shakespeare play as a representation of a performance (potential or actual), or more abstractly as a depiction of interactions among fictional entities with no particular relationship to a stage performance, the editor normally steps in to rationalize the actions and interactions of the entities depicted. This intervention affects the dialogue much less than it does what we call the structural elements-the act-and-scene division, the stage directions, the speech prefixes, the line numbering. As M. J. Kidnie observes, Roman Ingarten calls this domain the nebentext, or "side text," which he characterizes as essential to the performance text and yet secondary to the "main text" of the spoken words. ${ }^{50}$ Kidnie further notes how R. B. McKerrow, writing from an editor's perspective, identifies this sort of textual scaffolding as an area over which the editor exerts considerable control, for, as McKerrow points out, the form of such content has historically been due to the producers, rather than authors, of performance texts (and therefore does not fall under the protective aegis of "authorial intent"). ${ }^{51}$ With these elements, editors have the most

\footnotetext{
${ }^{50}$ M. J. Kidnie, “Text, Performance, and the Editors: Staging Shakespeare's Drama," Shakespeare Quarterly 51.4 (2000): 460-61.

${ }^{51}$ Ronald B. McKerrow, Prolegomena for the Oxford Shakespeare: A Study in Editorial Method (Oxford: Clarendon Press, 1939), 19, qtd. in Kidnie, “Text, Performance, and the Editors,” 461.
} 
latitude to impose their own convictions on the text and the most responsibility to their readers to manage the relationship between the text that is in front of them and the performances that lie behind it. The structural elements also form a part of the text that receives the most editorial refinement in terms of how precisely it functions to elucidate and organize the text, having a direct impact on the level of granularity at which the text-as-model can function. Accordingly, it should not surprise us that it is the structure of the text that has experienced the greatest amount of technological refinement in terms of how it is expressed on pages and screens, and how the various elements of this structure interrelate.

This refinement has created a trajectory of ever-increasing specificity in not only how the scaffolding describes the text (such as through increasingly granular and unambiguous speech prefixes and stage directions) but also how it indexes the text. The result of this increased specificity is a similar increase in the precision with which editors and readers alike are able to reference fragments of text, compare Shakespeare texts to one another and to those of other authors, perform quantitative analysis, and model various textual or performance phenomena. ${ }^{52}$ The first gesture toward a system of specification in Shakespeare's texts came in the practice of breaking up playtexts into acts and scenes. The first instance of any real division within the early printed Shakespeare playtexts was the Othello quarto of 1622, which contained divisions for acts 2,4 , and 5. Act and scene divisions were otherwise nonexistent in Shakespeare's early texts until the First Folio, and even here they were not applied with much consistency. Subsequent editions paid more attention to these divisions, and, after Nicholas Rowe introduced consistent act and scene divisions for all the plays in his Works of William Shakespeare (1709), nearly every major collected works edition has included these types of division. The editors of most of these editions also made a conscious effort to make them more systematic and regular. ${ }^{53}$ Few early editors, however, show a greater level of investment in the task of establishing a precise system of reference for Shakespeare than Edward Capell in his collected works of 1768.

As is clear from his introduction to this edition, Capell took issue with the inconsistent treatment of the playtexts in the early quartos, which he consulted in creating his edition. Capell expresses particular concern with the inexact handling of the structural elements of the plays contained in his primary sources: "Division of acts and scenes, they have none; ... Entries of persons are extreamely imperfect in them, (sometimes more, sometimes fewer than the scene requires) and their Exits are very often omitted; or, when mark'd, not always in the right place; and few scenical directions are to be met with throughout the whole.... [T] he reigning fault of all is in the measure: prose is very often printed as verse, and verse as prose; or, where rightly printed verse, that verse is not always rightly divided." ${ }^{54}$ Precision was a fundamental aspect of Capell's plan for his edition of Shakespeare. One of the few kind remarks he

\footnotetext{
${ }^{52}$ Throughout this section, the word "precision" will be used in the following sense: "The degree of refinement in a measurement, calculation, or specification." See OED Online (Oxford: Oxford UP, March 2017), http://www.oed.com/view/Entry/149667?redirectedFrom=precision (accessed 18 April 2017), s.v. "precision, n. and adj," 2c.

${ }^{53}$ Paul Werstine, "Episode 31: Editing Shakespeare," Shakespeare Unlimited, podcast, 9 September 2015, 16:53-17:26; Murphy, Shakespeare in Print, 60-61.

${ }^{54}$ Edward Capell, ed., Mr. William Shakespeare, his Comedies, Histories and Tragedies (London, 1768), 4.
} 
fity, the Table that is before the firf folio is here reprinted: and to it are added marks, put between crotchets, fhewing the plays that are divided; a fignifying-acts, $a \& f$ - acts and fcenes.

TABLE of Plays in the folio. 3

$$
\text { COMEDIES. As you like it. }[a \& f .]
$$

Tbe Tempeft. $[a \& f] \quad$.$T be Taming of the Shrew.$

The two Gentlemen of Vero-All is well, tbat Ends rvell. $[a$.

$$
\text { na.* }[a \& f .] \text { T'uelfe-Night, or what you }
$$

The Merry Wives of Wind- will. [a \& $f]$

for. $[a \& f$.

Meafure for Meafure. $[a \& f$.

The Comedy of Errours. * [a.] The Life and Deatb of King Mucb adoo about Notbing. [a.]

Loves Labour loft."

Midfommer Nigbts Dreame.*

[a.]

The Merchant of Venice. * [a.]
Tho Winters Tale. $[a \& f \cdot]$ HISTORIES. Jabn.* [a \& $f]$

The Life $\xi^{2}$ deatb of Richard the fecond. * [a $\&$ f.] $]$

The Firft part of King Henry the fourtb.* [a \& $\left.\int.\right]$
The Second part of $K$. Henry the firft.

the fourt $b . *[a \& f] \quad$.$T he Tragedy of Coriolanus. [a.]$

TheLife of King HenrytbeF ift. Titus Andronicus. * [a.]

The Firft part of King Henry Romeo and Juliet.*

the Sixt.

Timon of Atbens.

The Second part of King Hen. The Life and death of Julius the Sixt.

The Tbird part of King Henry The Tragedy of Macbetb. the Sixt.

The Life $\&$ Deatb of Ricbard The Tragedy of Hamlet.

the Third. * [a \& $\left.\int.\right]$ King Lear. [a \& $\left.\int.\right]$

The Life of King Henry the Otbello, the Moore of Venice. Eigbt. $[a \& \delta]$

$\begin{array}{cl}T R A G E D I E S . & \text { Antony and Cleopater. } \\ \text { [Troylus and Creffida] from Cymbeline King of Britaine. }\end{array}$ the fecond folio; omitted in $[a \& f$.

Figure 10. A table of the plays of the First Folio, along with indications of where act and scene divisions are to be found, from pp. 7-8 of Capell's introduction to his 1768 edition (see n. 54). Composite image reproduced by permission of the Thomas Fisher Rare Book Library, University of Toronto. 
makes about Heminge and Condell's work in compiling the Folio is that "some of their plays are divided into acts, and some others into acts and scenes; and that with due precision, and agreable to the Author's idea of the nature of such divisions." ${ }^{55}$ Regardless of the basis on which he presumed to know Shakespeare's opinions on act and scene divisions, what this rare compliment reveals is that, for Capell, establishing these elements of textual scaffolding was crucial to building an accurate model of the texts. Precise division of the plays was important enough to Capell that it merited more than just a single reference in his introduction; indeed, he went so far as to include a table that indicates where in the Folio these divisions are applied and where not (figure 10).

Most prescient to the current discussion about editors interfacing with the technology of their editions, and more specifically about the evolution of precision in mapping out and modeling performance texts, is Capell's use of the framework of the book itself to create a coordinate system that facilitated the examination and supplementation of the text. At this point in the history of Shakespeare editions, and indeed beyond the publishing of Capell's edition, assigning explicit line numbers to texts was not part of the conventional editorial infrastructure for Shakespeare, even though the eighteenth-century trend of including notes on the text necessitated some sort of system for linking those notes to the places in the text to which they referred. While every other major Shakespeare edition of the eighteenth century used either symbols or consecutive superscript letters or numbers to indicate places in the text to which notes apply, Capell appears to be the first to use the implicit line-numbering system of the page itself for reference. Each note (placed at the bottom of the page) is numbered according to the line number (counting from the top of each page, including stage directions), making it unnecessary to use markers within the text to signal a note. With this technique, Capell exploited an inherent feature of print-the fixed and discrete units of typographical lines on a printed page-to use as a more refined system for specifying fragments of text.

Capell's technique for marking notes had the immediate effect of making for a clean, accessible text, but the approach had more profound implications for how he, as an editor, worked, and for how his audiences could use the products of his labors. By having his edition of plays fixed in print, Capell now had an established indexing system for referring to fragments of the text with unusual precision. Not only did his edition provide him with the ability to point to lines by number, but the particular page-numbering convention employed in his edition also afforded an added level of reference. Capell's edition does not have a single consistent series of page numbers throughout each volume, as would be typical of such an edition, but rather features a separate page numbering series for each individual play within each three- or four-play volume. Having multiple consecutive series of page numbers in a volume (particularly a collected works) is by no means unheard of, and in fact can be witnessed in Shakespeare editions as far back as the First Folio. What is of interest in the case of Capell's edition is that the pattern of numbering each play individually is both consistent and clearly part of the edition's design rather than an exigency or accident of the printing process, and was evidently not motivated by the publisher's interest in having the option of selling individual plays. Signature series are continuous throughout each volume, suggesting a printing process free from interruptions that might otherwise explain a break in page numbering. Furthermore, single gatherings span two titles in various places, making the breaking up of copies for individual sale

${ }^{55}$ Capell, Mr. William Shakespeare, 7 (emphasis added). 


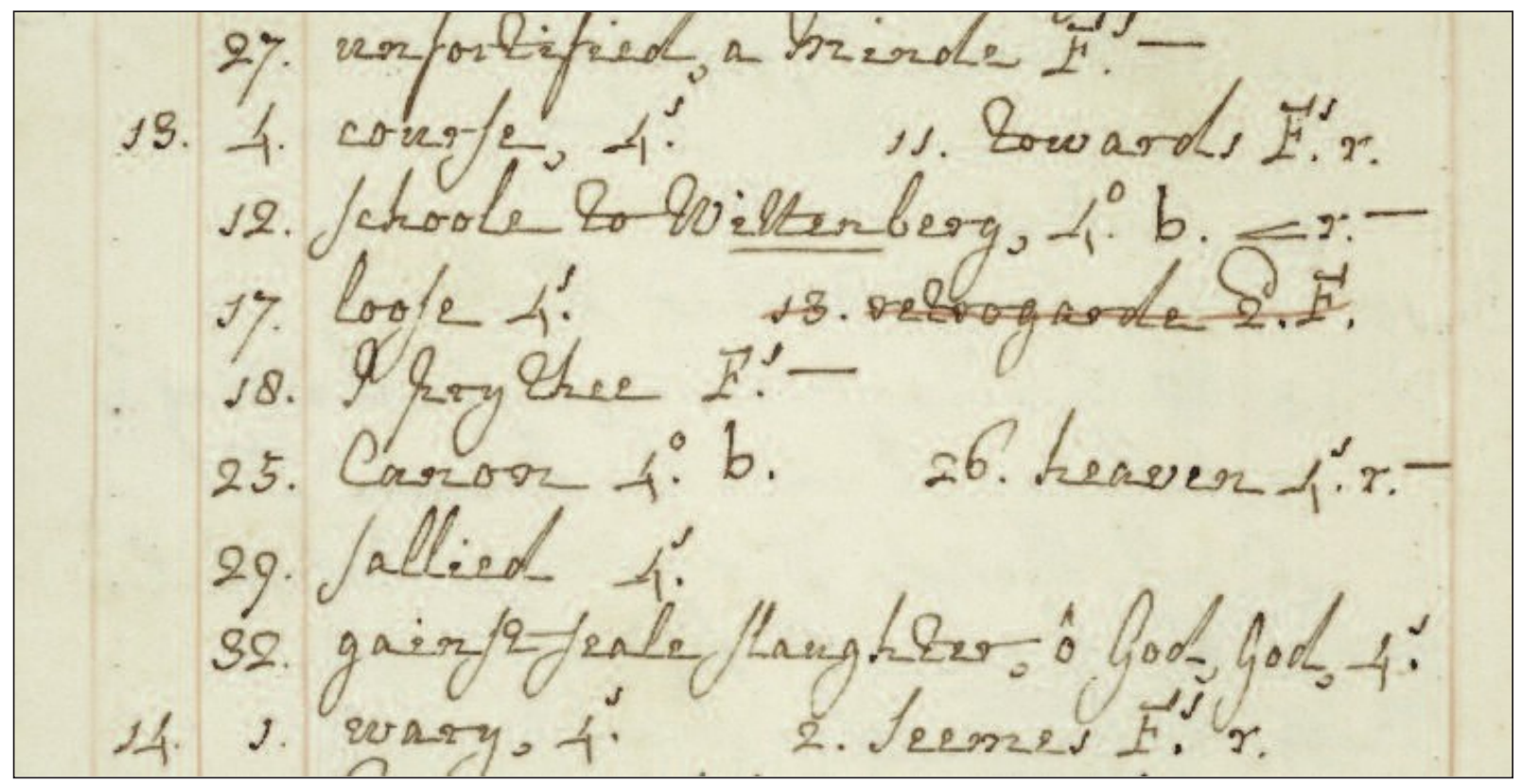

Figure 11. Capell's variant notes for Hamlet on p. 4 in his manuscript draft for Various readings [to Shakespeare] (see n. 56). Used by permission of the Folger Shakespeare Library under a Creative Commons Attribution-ShareAlike 4.0 International License.

extremely unlikely. These bibliographic features indicate that the individual numbering of each play was a conscious decision-a decision that turns the edition into a map with a coordinate system that enabled Capell to refer precisely to parts of the text by title, page, and line number.

Capell's use of this coordinate system appears in both his working papers and his published efforts. His manuscript variant notes, written between 1768 and 1775, are organized into a table that locates each variant by play, page, and line number, according to the 1768 edition (figure 11). ${ }^{56}$ Likewise, his Notes and Various Readings, the first part of which was published in 1774 and then withdrawn, uses the play/page/line number schema to guide readers to the specific parts of the text that the notes refer to, turning the edition into a pre-digital codec for deciphering Capell's editorial apparatus. ${ }^{57}$ Through Capell's exploitation of the indexable nature of page and mise-enpage, his edition provides a system that not only facilitates his own editorial labors but also provides a basis on which to append supplementary work, and supplies a guide for readers to interpret that work.

While Capell's technique of using the structure of the printed book itself as an indexing system provided him and others with the ability to refer to fragments of the playtexts with unprecedented precision, it was not until the first volumes of the Cambridge edition appeared in 1863 that line numbers became an explicit part of the scaffolding of the text. The Cambridge edition not only instituted printed line numbering running along the side of the type page, but also used these line numbers to

\footnotetext{
${ }^{56}$ Washington, DC, Folger Shakespeare Library, MS S.a.17-22, Edward Capell, Various readings [to Shakespeare] (ca. 1775).

${ }^{57}$ Edward Capell, Notes and various readings to Shakespeare (London, 1774).
} 
link the notes to the text they refer to. The Cambridge edition, created one hundred years after Capell first employed line numbers as reference nodes, was indebted to Capell for the collection of Shakespeare resources he donated to Trinity College, which provided the editors with what they described as "a mass of material almost unrivalled in amount and value, and in some points unique." ${ }^{58}$ But whether its editors ever consciously recognized it or not, this edition is also indebted to Capell's practice of using typographical line numbers in Shakespeare as a system for more precisely referencing textual fragments. In the same way that, as Mowat observes, Capell's editorial paradigm regarding variants in early sources (as taken up by Edmond Malone) "provided a matrix for Shakespeare editing that extended from the eighteenth through the early twentieth century, culminating in the 1860s in 'the great Cambridge Shakespeare,"' so too did Capell's use of the infrastructure of the printed text as a coordinate system provide a model for the Cambridge edition's own use of the linenumber system. ${ }^{59}$ And just as Rowe's consistent implementation of act and scene divisions was thereafter adopted by other editors, so did subsequent editions follow the Cambridge edition's explicit setting of line numbers as the new degree of refinement in specifying locations in Shakespeare's texts. A major edition published after 1863 that does not include printed line numbers is difficult to find.

The trajectory of increased precision made possible by editions' textual scaffolding continues past the nineteenth century into the digital editions of today. Charlton Hinman's application of through-line numbers to reference locations in the First Folio accurately and conveniently represents a significant step forward in how that text is studied and discussed, and operates as a model for how subsequent texts are laid out. ${ }^{60}$ Digital editions such as the ISE and the ENVS use a through-line numbering system as the basis for their XML identifiers and as a common navigational system. An XML identifier (XML:id) — the attribute of each element (such as a line) that provides that location in the text with a unique label—allows the ENVS's developers (as well as anyone else who takes advantage of their open-source code) to link data to and from these markers, and perform numerous forms of automated analysis.

The New Folger Library Shakespeare editions edited by Mowat and Werstine exploit the technology of the book in their own way to create enriched editorial opportunities for referencing, such as the technique of including glosses and other notes on the page facing the playtext. While this technique by no means originates with these editions, it is a technique that, as applied by Mowat and Werstine, has solidified the

\footnotetext{
${ }^{58}$ William George Clark, John Glover, and William Aldis Wright, eds., The Works of William Shakespeare, vol. 1 (Cambridge: Macmillan, 1863-66), x.

${ }^{59}$ Barbara A. Mowat, "The Reproduction of Shakespeare's Texts," in The Cambridge Companion to Shakespeare, ed. Margreta de Grazia and Stanley Wells (Cambridge: Cambridge UP, 2001), 13-30, esp. 18.

${ }^{60}$ While Hinman's use of through-line numbers was a significant event in Shakespeare studies, and particularly in the study of the Folio, there are a number of Shakespeare editions containing a throughline numbering (TLN) system that predate Hinman. See, for example, the Bankside Shakespeare edition edited by Appleton Morgan (New York: The Shakespeare Society of New York, 1889), which compares early witnesses of plays with their state in the Folio in a facing page arrangement, with through-line numbering of both texts throughout, including lines of stage directions. For critiques of Hinman's decision to exclude the Folio's nondramatic text from the TLN referencing system, see Thomas L. Berger, "The New Historicism and the Editing of English Renaissance Texts," in New Ways of Looking at Old Texts: Papers of the Renaissance English Text Society, 1985-1991, ed. W. Speed Hill (Binghamton, NY: Medieval and Renaissance Texts and Studies, 1993), 195-97, esp. 196; David C. Greetham, The Pleasures of Contamination: Evidence, Text, and Voice in Textual Studies (Bloomington: Indiana UP, 2010), 62-63; and Galey, The Shakespearean Archive, 84.
} 
editions' place as a powerful teaching tool. Furthermore, the way the notes use the linenumbering system of the playtext as reference points also makes them particularly conducive to adaptation into hypertextual environments, such as the Folger editions eBooks. ${ }^{61}$

As another project based on these editions, FDT introduces a still deeper level of precision through its application of XML:id attributes. Each line of each play is labeled with both the print editions' act/scene/line designation and through-line numbers specific to the Folger editions (called "Folger Through Line Numbers" [FTLN] to avoid possible confusion with Hinman's standard). But FDT goes even further, by providing each word, each piece of punctuation, and even each space with its own unique identifier, so that not only each line but also each fragment within that line can be indexed, referenced, and analyzed precisely. FDT's application programming interface (API), a work in progress that operates as a test bed for Poston (its creator) to explore new ways of modeling the text through manipulating its reference points, offers a working example of the level of precision enabled by FDT's XML:ids. In one of its most basic functions, the API's FTLN function allows the user to query a specific through-line number, which will return information on that line's act/scene/ line number, the speech it belongs to, the speaker who delivers it, its type (verse or prose), and the text of the line. See, for example, http:// www.folgerdigitaltexts.org/Ham/ftln/0323. The line itself also operates as a set of links that can be used to drill still deeper. Users can click any word within that line to open the API report for that specific word, including its XML:id, the speech, FTLN, and act/scene/line reference. The API report even provides the opportunity to view the word in the EEBO-TCP N-gram viewer. See, for example, http://www.folgerdigitaltexts.org/Ham/word/w0050250.

From the 1622 Othello quarto's first gestures toward division of the playtext into acts to the minute delineation of textual fragments through the use of modern XML schemas, the trajectory of refining the editorial infrastructure of Shakespeare's texts traces an evolution that crosses the boundaries of media. Several scholars have pointed out that current digital methodologies seemingly necessitate precision handling, as they are characterized by what McCarty calls the "twin computational requirements of complete explicitness and absolute consistency" and by what Matthew Kirschenbaum calls "the exquisite precision of their internal environments," which are "functionally defined by enormous amounts of documentary information, and in a far more systematic and regularized manner than manuscripts and books." ${ }^{12}$ However, what is revealed by the development of textual scaffolding throughout the history of Shakespeare editing, and particularly by the emergence of reference systems such as line numbers, is that increasing the precision with which textual fragments can be indexed, referred to, and recalled has long been a desideratum of Shakespeare's editors, and the means for achieving increasingly precise editorial interfaces have historically been discovered within the mechanics of the physical materials that house the texts-in other words, within the book as machine.

\footnotetext{
${ }^{61}$ The final volumes of the eBook series of the Folger editions were released on 8 November 2016. These eBooks, to be distinguished from the static eBook series released in 2011, feature links between playtext and notes (glosses, textual notes, and longer notes), as well as all the special tools and accessibility features of modern eBooks.

${ }^{62}$ McCarty, Humanities Computing, 5. Matthew G. Kirschenbaum, "Editing the Interface: Textual Studies and First-Generation Electronic Objects," TEXT 14 (2002): 15-51, esp. 48.
} 


\section{Conclusion: the Moving Parts of Future Shakespeare Editions}

In what ways, then, does the form of the editorial model, such as those constructed using increasingly sophisticated reference tactics, facilitate or preclude knowledge of the plays themselves? From early concordances to modern digital visualizations, the editorial interfaces that allow for increasingly precise and articulate analyses of large bodies of texts appear to increase opportunities for fresh discoveries. However, as Joseph Agassi discusses, increases in precision do not as a matter of course invalidate discoveries made using less precise standards, nor can trends observed on the whole determine with any certainty the properties of its individual features. ${ }^{63}$ In other words, while precise handling of minute textual units can allow for analyses that reveal trends in the text as a whole, whether the observed trends apply to any discrete unit within the text is indeterminable from the observation of the trend alone.

Furthermore, the more precisely a standard of division is applied, the more that standard is colored by the editor's particular set of beliefs about the text. As Agassi puts it in relation to observations in physics, increased precision occurs "under conditions specified by a theory." 64 For example, if the unit of precision is the line, then the editor's theory of lineation becomes crucially important. If the primary concern is metrical analysis, then how should prose be treated, given that it is broken into typographical lines due to the exigency of the page rather than its formal characteristics? For verse lines, how should turn-under lines be treated? If the text is a transcription from a quarto or the Folio, how should the encoding handle so-called compositor poetry, where a struggling compositor has awkwardly turned prose into verse (or vice versa) to fill up (or conserve) poorly estimated available space in the forme while casting-off copy? ${ }^{65}$ If the unit of precision is to be the word (for rhetorical analysis, for instance), what is the status of elisions or hyphenated compounds-are they to be considered one or more discrete units? Editorial beliefs about the nature of textual division are implicit in decisions about such divisions regardless of the level of precision involved (as Capell's editorial belief that the First Folio's act and scene divisions accord with Shakespeare's intentions exemplifies).

As Kidnie points out, the modern conception of Shakespeare's plays as first and foremost performance texts has by now become widespread, and "this sea change in the study of early modern drama has led to an articulated desire to produce texts that explore the plays' "theatrical dimensions."'66 The negative implication of this observation is that our editions of Shakespeare have thus far failed in this task. The evolution of the editorial interfaces that turn material texts into such powerful engines for exploring, referencing, and analyzing elements of Shakespeare's works has perhaps progressed in ways that are disadvantageous to the conception of the play as performance. Indeed, in a performance workshop of the quarto text of King Lear, Michael Warren found the inexactness of the early text's stage directions to be "in an odd way admirable" - the same inexactness that editors throughout the history of Shakespeare publishing have sought to eliminate-because it leaves staging more open

\footnotetext{
${ }^{63}$ Joseph Agassi, "Precision in Theory and Measurement," Philosophy of Science 35.3 (1968): 287-90, esp. 287.

${ }^{64}$ Agassi, “Precision," 289.

${ }^{65}$ For a clear explanation of this problem, see Eleanor Prosser's chapter "Textual Changes by the Folio Compositors," in Shakespeare's Anonymous Editors: Scribe and Compositor in the Folio Text of "2 Henry IV" (Stanford, CA: Stanford UP, 1981), 51-121

${ }^{66}$ Kidnie, "Text, Performance, and the Editors," 456.
} 
to interpretation. ${ }^{67}$ For Warren, the observation of the workshop underscores how "the very process of our work [as scholars] is necessarily fixing, restrictive, reductive-we feel that we cannot leave things open, but must decide when Lear dies, even though the theatre knows that it is a place of endless variant possibilities." Kidnie identifies the conflict at the core of this comparison: "It is the editors who require Lear's moment of death to be pinned down with precision, while the theater knows that to attempt to identify such a moment is to ask the wrong question of a dramatic text."68

A successful model is one that invites such questioning, and lets us know when we are asking the wrong ones, as Kidnie notes. It is likely that satisfying the desire for editions that respect the ontologies of performance will require editors to think beyond the limits of the stage direction as the primary component of the editorial scaffolding where the play as performance is to be modeled, and to interrogate more radically today's editorial interfaces and identify areas for innovating their capacity for representing, referencing, and analyzing the play specifically as performance. Capell himself made gestures in this direction, even as he was innovating the editorial infrastructure of his edition in other ways. Capell attempted to introduce a system of punctuation that would signal various performance elements, including the dash to indicate a change of address (familiar to readers of Shakespeare today), a double-cross to indicate a prop being delivered by a character during a speech, and even a superscript dash to make explicit the irony in a given line, which would be indicated onstage by an actor's tone of voice or expression. By all accounts, Capell's experiment was a failure-perhaps because the only legend explaining the marks was printed in a separate, unrelated book, which Capell never references in his edition-but his efforts nonetheless provide an instructive example of an editor experimenting with the structure of the edition to model the texts as performances. ${ }^{69}$

To offer a final example of a modern experiment in this vein, let us turn back to the editorial problem that Kidnie and Warren touch on: that of representing moments of death in performance versus in the text. FDT approaches the editorial decision of the moment of death by using its universal referencing system to allow for the declaration of a range of possible points in which a character could die, rather than only a single point. In King Lear, for instance, metadata pertaining to Cordelia encoded into the XML contains the following range declaration: <death notBefore-custom="ftln-3280" notAfter-custom="ftln-3557" / > This declaration states that Cordelia dies not before

\footnotetext{
${ }^{67}$ Michael J. Warren, “The Theatricalization of Text: Beckett, Jonson, Shakespeare," in New Directions in Textual Studies, ed. Dave Oliphant and Robin Bradford (Austin, Tx: Harry Ransom Humanities Research Center, 1990), 39-59, esp. 57-58, qtd. in Kidnie, "Text, Performance, and the Editors," 458.

${ }^{68}$ Kidnie, "Text, Performance, and the Editors," 458. What is really of interest to the present conversation, rather than simply contrasting the nature of performance to the nature of editing, are the ways in which the precision characteristic of modern editing can be seen to foreclose interpretive possibility (manifested here as performance). It should also be noted that unambiguous stage directions are by no means an exclusively modern phenomenon. There are many very early examples of stage directions that explicitly locate events such as characters' deaths: one such can be found in the playhouse manuscript of The Second Maiden's Tragedy (1611; see W. W. Greg's 1909 Malone Society edition, p. 69), and a good number of deaths are explicitly noted in the First Folio itself, such as Cleopatra's and Charmian's at 5.2.373 and 5.2.390, respectively (see Mr. William Shakespeares Comedies, Histories, \& Tragedies [London, 1623], STC 22273, sig. zz2r). Furthermore, as Tiffany Stern indicates in her book Rehearsal from Shakespeare to Sheridan (Oxford: Clarendon Press, 2000), the genre of the performance workshop is itself an anachronistic method of interrogating Elizabethan performance practices, and therefore the conclusions one may draw from it are limited.

${ }^{69}$ The book in question is Capell's Prolusions; or, Select Pieces of Ancient Poetry (London, 1760).
} 
Folger through-line number 3280 (when she last walks offstage;

https: / / www.folgerdigitaltexts.org/ ?chapter=5\&play=Lr\&loc=ftln-3280) and not after 3557 (when Lear carries her body back onstage;

https: / / www.folgerdigitaltexts.org/?chapter=5\&play=Lr\&loc=ftln-3557). If a usermaker wanted to extend this interpretive range, perhaps to reflect Lear's own uncertainty, or state of denial, about Cordelia's death, he or she could easily edit the code to set the "notAfter" attribute to as far as 3625 (Lear's final line; https://www.folgerdigitaltexts.org/?chapter=5\&play=Lr\&loc=ftln-3625), or even remove it entirely and leave open the question of whether she dies at all. This is but one example of how innovating on the affordances of existing editorial interfaces may allow for the modeling of texts as performance.

What then of the textual scholar's role in relation to the variety of new media that depict Shakespeare in performance? An adequate answer to that question will likely lead beyond the traditional dichotomies of page versus stage and text versus performance, which seem increasingly inadequate to the complexities of digital media. As W. B. Worthen points out, "Shakespearean drama has, for a century now, had several sites of performance" thanks to an array of new media that challenge any simple notion of text: "Shakespeare speaks to us from the pages of a stunning variety of printed materials; from the radio; from phonograph records, reel-to-reel cassette tapes, compact audio disks; from the big screen in the movie theatre and (now [i. e., 2007], with much greater frequency) from videotape and digital video disk recordings on the television screen." ${ }^{\prime 70}$ Compare D. F. McKenzie's challenge to bibliographers nearly three decades ago to rethink the traditional notion of text to include "verbal, visual, oral, and numeric data, in the form of maps, prints, and music, of archives of recorded sound, of films, videos, and any computer-stored information, everything in fact from epigraphy to the latest forms of discography." ${ }^{\prime 71}$ Worthen's point about the variety of Shakespeare media is a reminder that McKenzie's challenge to textual scholars- to think holistically and inclusively about forms of textual transmission-still remains provocatively before us.

Performance complicates McKenzie's challenge. As Worthen goes on to argue, "While live theatrical performance remains for many people the privileged site of performance, having - like writing (though perhaps not like print)—an ontological connection to the media in which Shakespeare composed his plays, the identity of Shakespearean drama no longer seems to shuttle solely between the page and the stage."72 Digital models for performance may yet offer an intermediate space between page and stage, though any successful digital model will need to steer a careful path between complexity and reductivism. For example, while a digital project such as the Simulated Environment for Theatre (SET) may seem to offer a digital counterpart to Craig's theatrical models, its framing within the traditional digital humanities paradigm of textvisualization means that its source texts must be normalized as machine-readable data. While the SET project promisingly models performance spaces with lowresolution 3D graphics, it falls short of a serious attempt to model with equal complexity the textual variants, emendations, and multiple versions that make Shakespeare's texts such challenging artifacts of study. ${ }^{73}$ Digital modeling of

\footnotetext{
${ }^{70}$ W. B. Worthen, "Performing Shakespeare in Digital Culture," in The Cambridge Companion to Shakespeare and Popular Culture, ed. Robert Shaughnessy (Cambridge: Cambridge UP, 2007), 227-47, esp. 228.

${ }^{71}$ D. F. McKenzie, Bibliography and the Sociology of Texts (Cambridge: Cambridge UP, 1999), 13.

${ }^{72}$ Worthen, "Performing Shakespeare," 228.

${ }^{73}$ Jennifer Roberts-Smith et al., "Visualizing Theatrical Text: From Watching the Script to the Simulated Environment for Theatre (SET)," Digital Humanities Quarterly 7.3 (2013): para. 32,
} 
Shakespeare texts has a long way to go before it approaches the synthesis represented by the Cranach Press Hamlet as an artifact of print and performance, created with equal regard for the theatrical and bibliographical dimensions of Shakespeare's works.

Yet wrestling with new media is what Shakespeareans do. Facing the new medium of photolithography, Staunton found that the typical editorial controls and affordances of moveable type-based editions were denied him, without yet being replaced by a comparable editorial model for the new type of text. We see in Staunton's proof corrections a frustration with the lack of control over the photolithographic text similar to what many scholars may feel regarding the seemingly indistinct, fluid nature of performance texts, such as audio or video recordings, that do not fit the conventional editorial model of the printed edition. However, just as producers of editions in the past-including Craig, Staunton, Furness, Capell, and Mowat and Werstine-struggled with and ultimately reshaped the editorial infrastructures within which they labored, innovations in editorial interfaces for alternative-media Shakespeare texts that provide stable and reproducible systems for indexing, referencing, and analysis may very well provide new affordances for exploring these materials. That Shakespeare's texts still require this exploration after more than four centuries says something about their original construction and ongoing reception alike. As a similar regenerative practice, modeling in the humanities requires us to imagine digital Shakespeare texts not as passive data, but as media-specific, operative representations-in other words, as theories with moving parts.

http:/ digitalhumanities.org:8081/dhq/vol/7/3/000166/000166.html 